\title{
A novel multigene expression construct for modification of glycerol metabolism in Yarrowia lipolytica
}

\author{
Ewelina Celińska* and Włodzimierz Grajek
}

\begin{abstract}
Background: High supply of raw, residual glycerol from biodiesel production plants promote the search for novel biotechnological methods of its utilization. In this study we attempted modification of glycerol catabolism in a nonconventional yeast species Yarrowia lipolytica through genetic engineering approach.

Results: To address this, we developed a novel genetic construct which allows transferring three heterologous genes, encoding glycerol dehydratase, its reactivator and a wide-spectrum alcohol oxidoreductase under the control of glycerol-induced promoter. The three genes, tandemly arrayed in an expression cassette with a marker gene ura3, regulatory and targeting sequences (G3P dh promoter and XPR-like terminator, 28S rDNA as a target locus), were transferred into Yarrowia lipolytica cells. The obtained recombinant strain NCYC3825 was characterized at the molecular level and with respect to its biotechnological potential. Our experiments indicated that the novel recombinant strain stably borne one copy of the expression cassette and efficiently expressed heterologous alcohol oxidoreductase, while glycerol dehydratase and its reactivator were expressed at lower level. Comparative shake flask cultivations in glucose- and glycerol-based media demonstrated higher biomass production by the recombinant strain when glycerol was the main carbon source. During bioreactor $(5 \mathrm{~L})$ fed-batch cultivation in glycerol-based medium, the recombinant strain was characterized by relatively high biomass and lipids accumulation (up to $42 \mathrm{gDCw}_{\mathrm{DC}}^{-1}$, and a peak value of $38 \%$ LIPIDS of DCW, respectively), and production of high titers of citric acid (59 $\left.\mathrm{g} \mathrm{L}^{-1}\right)$ and 2-phenylethanol (up to $1 \mathrm{~g} \mathrm{~L}^{-1}$ in shake flask cultivation), which are industrially attractive bioproducts.

Conclusions: Due to heterogeneous nature of the observed alterations, we postulate that the main driving force of the modified phenotype was faster growth in glycerol-based media, triggered by modifications in the red-ox balance brought by the wide spectrum oxidoreductase. Our results demonstrate the potential multidirectional use of a novel Yarrowia lipolytica strain as a microbial cell factory.
\end{abstract}

Keywords: Yarrowia lipolytica, Novel genetic construct, Glycerol metabolism, Heterologous expression, Biomass

\section{Background}

Current trends in biotechnology encourage utilization of waste and renewable resources for production of highvalue-added chemical compounds. High supply of raw, residual glycerol from biodiesel production plants promote the search for novel methods of its utilization [1]. In a pursue of efficient exploitation of this byproduct, multiple bioprocesses have been developed: production of 2,3-butanediol [2], 1,3-propanediol [3], vitamin $\mathrm{B}_{12}$

\footnotetext{
* Correspondence: celinska@up.poznan.pl

Department of Biotechnology and Food Microbiology, Poznan University of Life Sciences, Wojska Polskiego 48, Poznań 60-627, Poland
}

[4], propionic acid [5], ethanol [6], succinic acid [7], lipids [8], citric acid [9,10] and more [11].

Yarrowia lipolytica is a dimorphic, nonconventional yeast species with unique metabolic properties, known for its efficient growth on raw glycerol from biodiesel production plants. Interest in this species stems from its metabolic potential expressed in exceptional ability to utilize and accumulate hydrophobic substances [12-14] as well as to produce high amounts of valuable metabolites, such as: citric and isocitric acid [15,16], succinic acid [17], erythritol [18], $\gamma$-decalactone [19] and biosurfactants [20]. Y. lipolytica is also frequently employed in the production of SCP and SCO from waste bioresources, such as waste

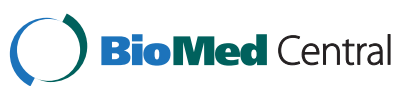

(c) 2013 Celinska and Grajek; licensee BioMed Central Ltd. This is an open access article distributed under the terms of the Creative Commons Attribution License (http://creativecommons.org/licenses/by/2.0), which permits unrestricted use, distribution, and reproduction in any medium, provided the original work is properly cited. 
cooking oil [21], agro-industrial residues [22], industrial derivatives of tallow [23], palm-oil mill or olive-oil mill wastewater $[24,25]$. Y. lipolytica is non-pathogenic for human and is considered a GRAS species, approved for numerous industrial applications [26]. This fact, together with its exceptional performance in utilization of different raw biomaterials and their bioconversion into high-valueadded bioproducts stimulates its frequent application in industrial processes [27].

Currently, $Y$. lipolytica constitutes a recognized system for heterologous proteins expression [28]. Direct comparison of different expression platforms: Y. lipolytica, Saccharomyces cerevisiae, Pichia pastoris, Arxula adeninivorans, Hansenula polymorpha, Kluyveromyces lactis, Schizosaccharomyces pombe $[29,30]$ indicated that $Y$. lipolytica is characterized by several advantageous traits for heterologous proteins expression over the other expression systems. In the literature one can find several detailed review papers on the applied strategies, used vectors and heterologous proteins expressed in Y. lipolytica [31,32]. Apart from exploitation as a heterologous protein expression platform, efforts towards improvement of $Y$. lipolytica native metabolic properties have been pursued. Successful metabolic engineering towards increasing lipid accumulation was recently carried out using two independent approaches [33] and [13,34]. In the former report, the engineered strain was modified trough co-expression of two genes involved in triacylglycerols (TAGs) biosynthesis - diacylglycerol acyltransferase (DGA1) and acetyl-CoA carboxylase (ACC1), the final and the first activity of the pathway (see Figure 1). In the latter strategy, a deletion recombinant strain lacking all six isozymes of acyl-CoA oxidase (lack of TAGs mobilization in the stationary phase, $\Delta$ pox1-6) and, due to disruption of the GUT2 gene ( $\triangle g u t 2)$, securing higher provision of G3P (glycerol-3-phosphate) for the lipid synthesis, accumulated nearly four-fold higher amounts of total lipid per g of DCW from oleic acid [13]. Another application of metabolic engineering strategies allowed for development of a $Y$. lipolytica strain able to produce carotenoids $[35,36]$. This great success has been repeated and reported recently [37].

The main objective of the presented work is to develop a genetic construct bearing several heterologous genes natively involved in glycerol metabolism, and expressing the genes in glycerol-induced manner. To this end,

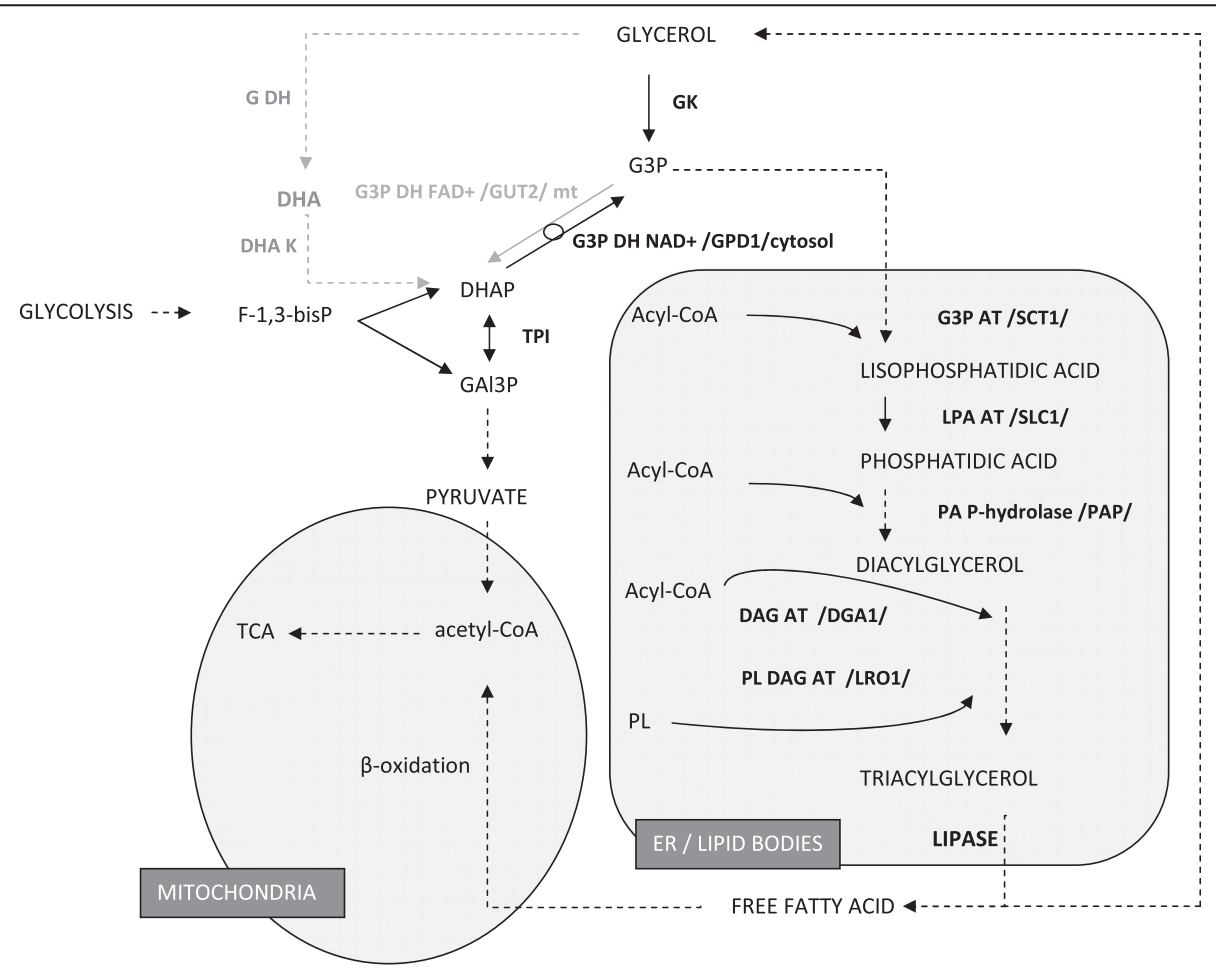

Figure 1 Glycerolipids turnover in Y. lipolytica. GK - glycerol kinase, G3P - glycerol-3-phosphate, G3P DH NAD+/FAD + - NAD+/FAD + -dependent dehydrogenase G3P (GPD1/GUT2 - genes encoding respective activities), DHAP - dihydroxyacetone phosphate, TPI - triosephosphate isomerase, GAl3P - glyceraldehyde-3-phosphate, F-1,3-bisP - fructose-1,3-bisphosphate, G DH - glycerol dehydrogenase, DHA - dihydroxyacetone, DHA K -DHA kinase, G3P AT - G3P acyltransferase, LPA AT, lisophosphatidic acid acyltransferase, PA P-hyrolase - lisophosphatidic acid phosphatase, DAG AT - diacylglycerol acyltranferase, PL DAG AT - phospholipids:diacylglycerols acyltransferase, PL - phospholipids. Grey dashed line - pathways inactive when grown on glycerol. Organelles are indicated by grey areas. (based on [34], [63], KEGG database; http://www.genome.jp/kegg/pathway.html). 
genes encoding a vitamin $\mathrm{B}_{12}$-independent glycerol dehydratase dhaB1 and its reactivator dhaB2 from Clostridium butyricum, and a wide-spectrum alcohol oxidoreductase dhaT from Shimwellia blattae are cloned under a native promoter of glycerol-3-phosphate dehydrogenase (G3P dh), described as glycerol-induced [38], with the first intron sequence and strong XPR2-like terminator. Thus, the activities which are natively involved in glycerol catabolism are expressed in glycerol-induced manner.

\section{Results and discussion}

\section{Construction of a novel expression integrative vector} dedicated for $Y$. lipolytica

The first key effect of the presented study is construction of a novel expression vector pYLG1 (Figure 2) bearing three heterologous genes (dhaB1, dhaB2, dhaT) and a selection marker gene (ura3). The overall length of the ready-to-transform expression cassette with ex vivo added flanks targeting integration at $28 \mathrm{~S}$ rDNA loci is over $13 \mathrm{~kb}$. The pYLG1 vector was assumed to fulfill the following requirements: transfer of heterologous genes involved in glycerol catabolism, induction of the genes expression in a glycerol-induced manner, integration of the genetic construct with the host genome and its stable bearing. These issues were addressed through the following approaches.

The pYLG1 vector presented in this work bears three heterologous genes, natively involved in glycerol metabolism. The genes dhaB1 and dhaB2 from C. butyricum encode a vitamin $B_{12}$-independent glycerol dehydratase and its reactivator (thoroughly characterized in [39]). No such activity, catalyzing glycerol dehydratation and synthesis of 3-hyroxypropanal, has been identified in $Y$. lipolytica, thus, we decided to investigate, whether its expression in this expression system would modify its glycerol metabolism. DhaB1-DhaB2 from C. butyricum is the only such activity independent of vitamin $B_{12}$ cofactor, described to date. Our preliminary experiments indicated that $Y$. lipolytica is unable to produce vitamin $\mathrm{B}_{12}$, and no activities involved in its production and transportation have been identified, to date (KEGG database). Therefore, glycerol dehydratase activity from $C$. butyricum was chosen for expression in $Y$. lipolytica cells. The second gene cloned in the PYLG1 vector encode a wide-spectrum alcohol oxidoreductase from S. blattae (formerly Escherichia blattae) [40]. In general, DhaT catalyses reversible reactions of

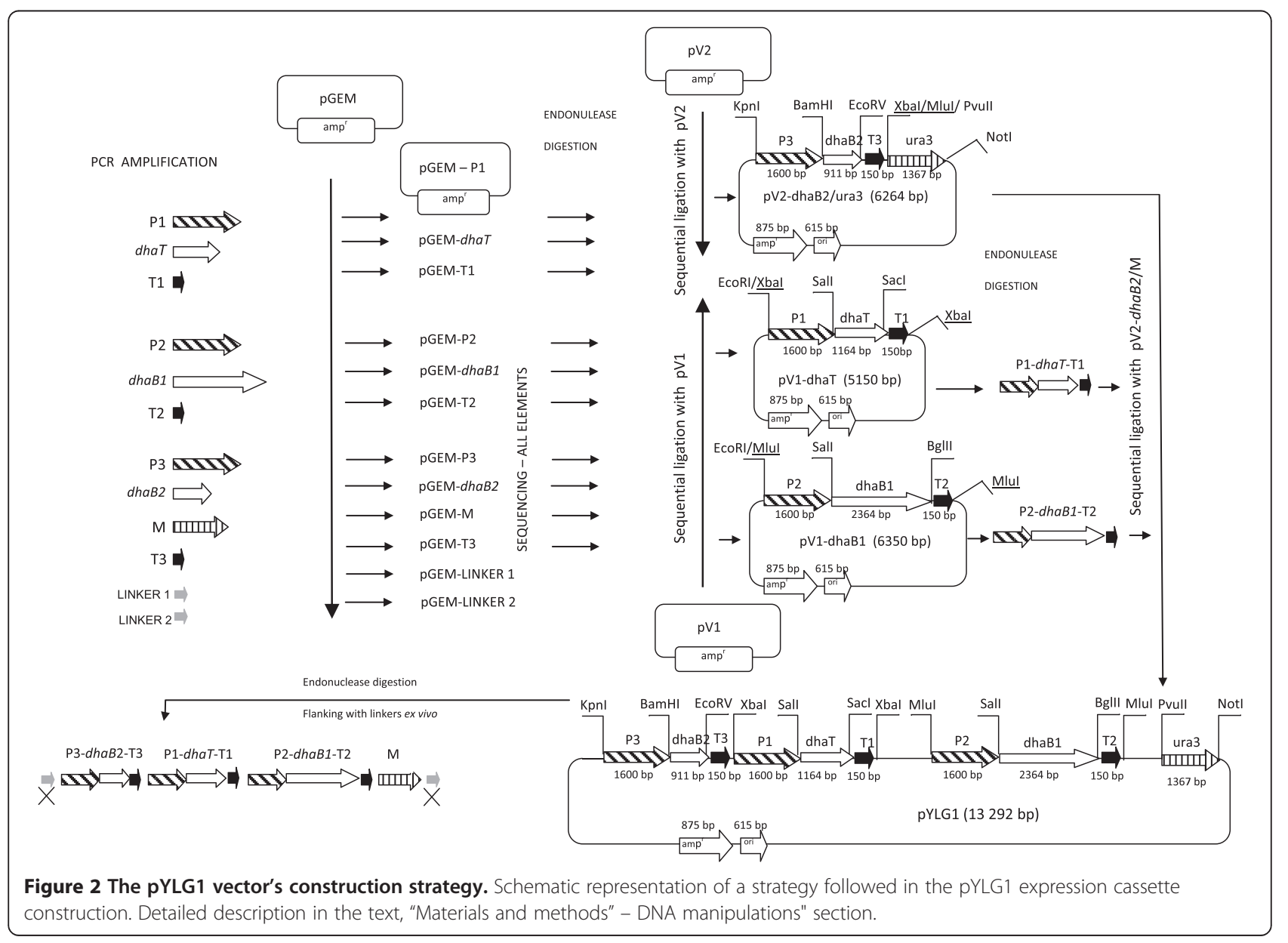


oxidation and reduction between multiple small molecule aldehydes and alcohols (BRENDA; http://www.brendaenzymes.info/). DhaT is a $\mathrm{NAD}(\mathrm{P}) \mathrm{H}$-dependent activity contributing to the red-ox balance maintenance in a cellular system.

Each heterologous gene was flanked with regulatory elements - glycerol-induced promoter of a gene encoding G3P dh (described in [38]) and XPR2-like terminator, frequently used in different genetic constructs for $Y$. lipolytica $[28,31,32]$. Both the information included in [38] and own analysis of the G3P dh promoter region confirmed the presence of a spliceosomal intron in the 5 ' region. According to the results presented in [38], downstream activating elements contained within this region significantly enhance expression of a reporter gene, cloned under the control of this promoter. Thus, a $1600 \mathrm{nt}$ fragment including the first intron sequence was cloned in three restriction variants in the pYLG1 vector.

The parental strain used in this study is an uracil auxotroph due to integration of a $S U C 2$ gene from $S$. cerevisiae at the ura3 (orotidine-5-phosphate) locus. The modification was completed and described in [41] with the use of pINA302 vector, generating a strain A18 with ura3-suc2+ phenotype. Exploitation of this strain allowed selection of the obtained recombinants bearing the pYLG1 expression cassette by complementation of the auxotrophy trait with ura3 gene contained within the vector.

The last requirement assumed for the genetic construct presented in this study was its integration with the host genome, enabling its stable bearing in the subsequent generations. It was fulfilled by flanking the expression cassette with 300 nt DNA fragments complementary to $28 \mathrm{~S}$ rDNA gene loci. rDNA is a frequent target for heterologous integration due to several reasons: nucleotide sequence available for many organisms, multiple integration sites per genome, integration into a transcriptionally active site, the possibility of post-transformation amplification of the heterologous fragment's copy number in the genome, if the selection pressure is appropriately manipulated [42-44]. In Y. lipolytica genome over 200 copies of rDNA clusters have been identified [45], resulting in such a number of potential integration sites.

The applied vector construction strategy (Figure 2) lead to development of the pYLG1 expression cassette used for transformation of the Y. lipolytica A18 competent cells.

\section{Characterization of the obtained recombinant $Y$. lipolytica NCYC3825 strain at the molecular level}

In a course of transformation procedure, $Y$. lipolytica NCYC3825 strain was obtained. The presence of all heterologous genes was confirmed by PCR amplification of the respective regions on the genomic DNA template
(Figure 3). The obtained strain was subsequently characterized at the molecular level.

\section{Copy number estimation}

In order to estimate the number of copies of the expression cassette integrated with the host's genome, a realtime PCR analysis was carried out on the genomic DNA template with a subsequent data processing according to [46]. The undertook approach allows estimation of copy number of any DNA fragment after comparison with a fragment of known number of copies. The obtained results indicated that the heterologous genes are present in one copy per genome of the recombinant strain. The final relative quantitation values obtained for dhaB1, $d h a B 2$, and $d h a T$ were $0.633,0.622$ and 0.627 , respectively. To verify the applied method, analogous reactions were set up on the genomic DNA template of the parental strain A18. The final relative quantitation values for dhaB1, dhaB2, and dhaT were 0.017, 0.055 and 0.029, respectively. The results of this analysis confirmed that the sequences were absent from the parental strain's genome. Presence of a single copy of the expression cassette was rather unexpected, since $28 \mathrm{~S}$ rDNA was targeted for integration. As mentioned earlier, over 200 copies of rDNA cluster were identified in $Y$. lipolytica genome. Thus, integration of higher number of expression

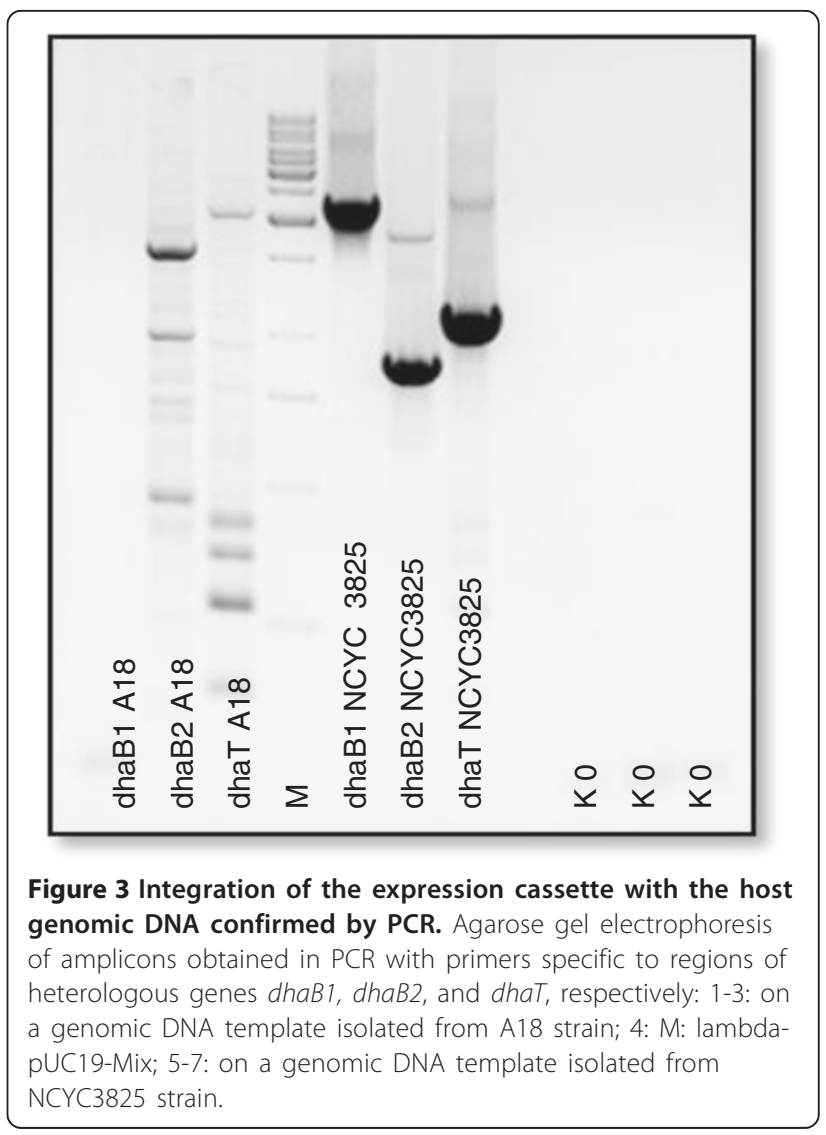


cassette copies was expected. Two possible reasons could contribute to such a result: short fragments of homology used as targeting sequences and low quantity of the expression cassette used for transformation. According to [43], $300 \mathrm{nt}$ is the minimal length of homology regions allowing integration occurrence, however, usually whole homologous genes, endonuclease digested in a central region, were used as the targeting elements. On the other hand, our experience show that even much shorter homology regions (60 nt) are sufficient for occurring an integration event.

\section{Stability assessment}

In the following step, stability of the expression cassette in the recombinant's genome was assessed through PCR amplification of the heterologous genes' regions on the genomic DNA template. Stability of the expression cassette was assessed in the following conditions: multiple (>40 times) passaging in the MMT agar selective medium, lyophilization followed by reviving process, and bioreactor culturing, when no selection pressure was maintained (uracil was contained in the medium). The obtained images of electrophoretic separation of amplicons indicated that during all of the applied conditions, the expression cassette was stably maintained in the host's genome.

\section{Gene expression analysis}

Expression of the heterologous genes in the novel expression system was analyzed through real-time quantitative PCR performed on the cDNA template obtained from the parental A18 and the recombinant NCYC3825 strain. The results expressed as fold change of the normalized expression level in the recombinant strain cells $v s$ the parental strain cells are presented in (Figure 4). No amplification products were obtained in the reaction with primers specific to XPR2-like terminator, indicating lack of genomic DNA contamination. As shown in (Figure 4) the expression level of clostridial genes, dhaB1 (1.56-fold increase) and dhaB2 (7.63-fold increase), is relatively low, when compared to the expression level of $d h a T$ (26.2-fold increase) gene; ura3 gene was analyzed as a positive control (19.2-fold increase). Since all the heterologous genes were cloned under the control of the same G3P dh promoter, the differences in the expression level should not result from differences in a number of transcription initiation events. Analysis of DNA sequences of the heterologous genes showed considerable differences in GC content, which for clostridial genes equaled $29 \%$, for dhaT - 59\%, and 50\% for Y. lipolytica genomic DNA. According to [47-49] significant differences in GC content between heterologous sequence and sequences native to the host genome can contribute to low expression efficiency of the heterologous sequence,

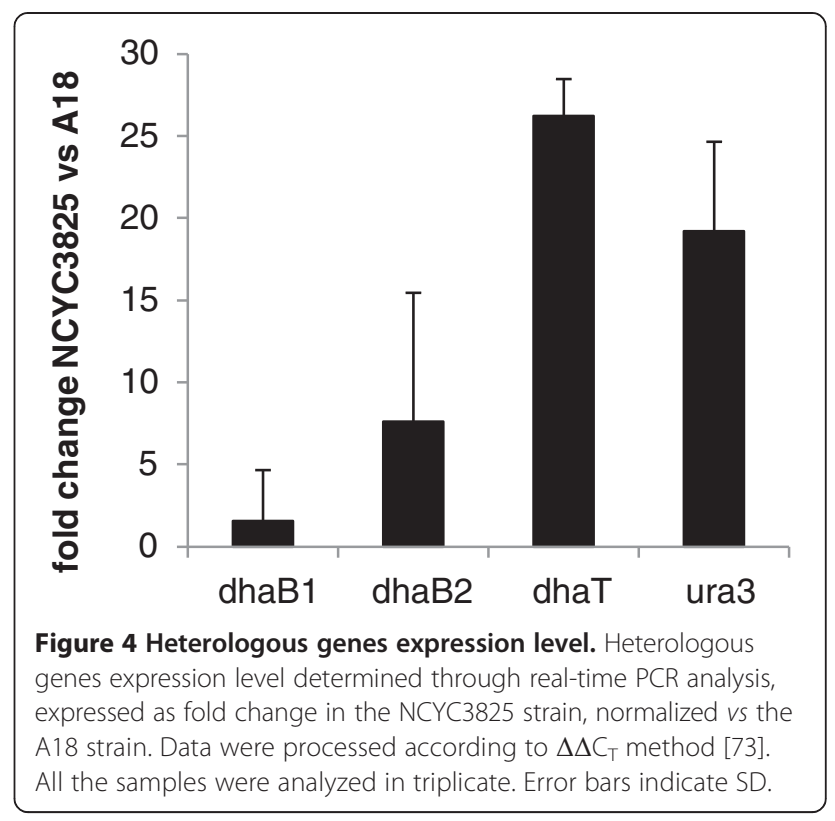

caused by premature transcription termination or improper maturation of mRNA. It is highly probable that the difference in GC content between $Y$. lipolytica genome and the clostridial genes contributed to lower expression efficiency. Codon usage optimization of the clostridial sequences could probably improve the expression efficiency. Such an approach was shown to improve the expression efficiency, when the donor of the expressed sequence and the host organisms were phylogenetically distant [50-52].

\section{Oxidoreductase activity in a new expression system}

Since DhaT cloned and expressed in $Y$. lipolytica NCYC3825 catalyzes multiple $\mathrm{NAD}(\mathrm{P}) \mathrm{H}$-dependent reactions of oxidation and reduction between various small molecular weight alcohols and aldehydes, the overall oxidoreductase activity assessment in the parental and the recombinant strain cells was carried out. To this end, flourophore staining and cytometric analysis were used. Results of this analysis are shown in (Figure 5). The recombinant NCYC3825 strain was characterized by over two-fold higher oxidoreductase activity when compared to the parental strain A18 ( $<<0.001$; t-Student's test). Such results could be attributed to heterologous activity of the DhaT oxidoreductase, however, also different physiological properties of the two compared strains could influence the obtained result, like more vigorous growth of the NCYC3825 prototroph.

The observed characteristics of the NCYC3825 strain were similar to those obtained in the $V H b+Y$. lipolytica strain [53], where a gene encoding hemoglobin from Vitreoscilla was expressed. Both strains were characterized by higher growth rate and oxygen consumption, 


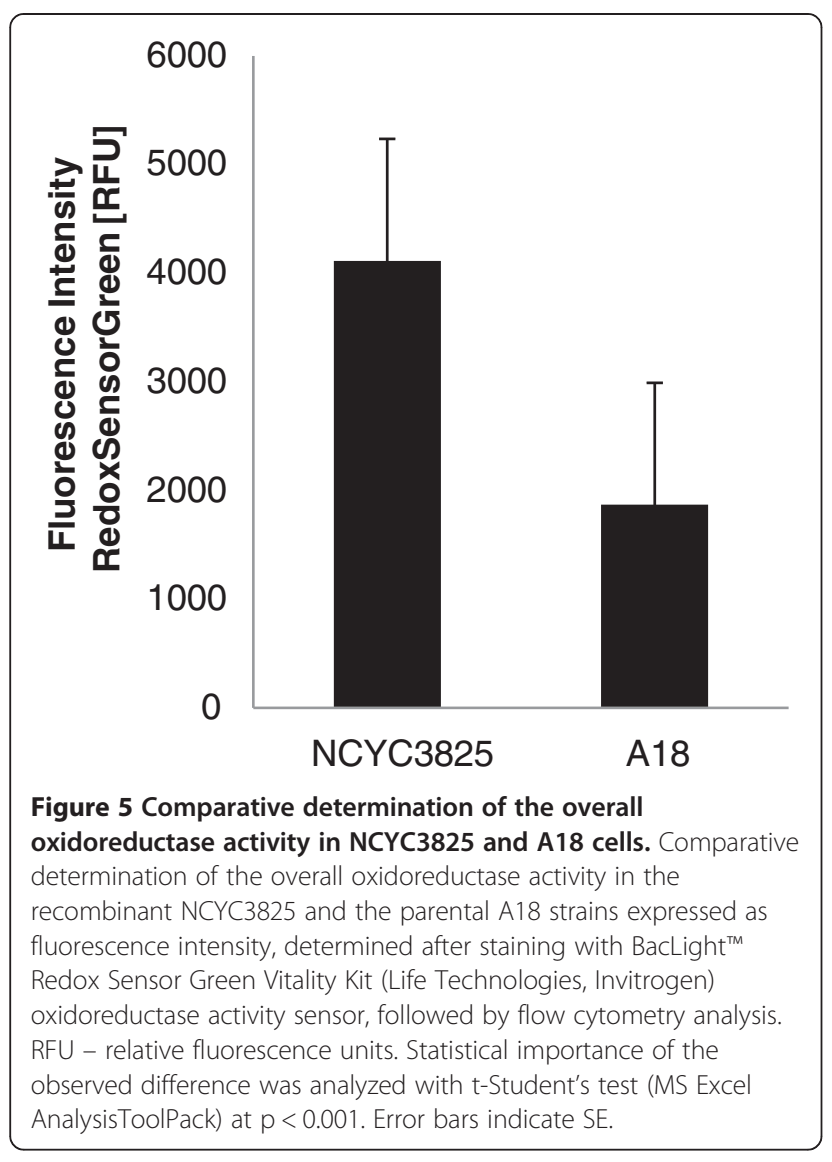

and by higher production of extracellular proteins. Multiple enzymatic activities and cellular processes contribute to development of these characteristics, thus it seems that a more general molecular process was modified in both of these strains. The expressed heterologous proteins posses different molecular roles, $\mathrm{NAD}(\mathrm{P}) \mathrm{H}$-dependent red-ox reactions (DhaT) and intracellular oxygen supply $(\mathrm{VHb})$, however, both are involved in the red-ox cofactor turnover. In the face of the obtained result regarding oxidoreductase activity in the NCYC3825 strain and the macroscopic characteristics of both, $\mathrm{NCYC} 3825$ and $\mathrm{VHb}$ + , strains, it can be postulated that modification of the red-ox potential mainly contributed to the observed differences between A18 and NCYC3825 strains. This statement is corroborated by the other literature data, where $\mathrm{VHb}$ gene was heterologously expressed and consequently lead to improvement of the modified strains' performance during cultivation [54-57].

\section{Performance of $Y$. lipolytica NCYC3825 recombinant strain during cultivation}

In this series of experiments the novel recombinant strain NCYC3825 was directly compared with its parental strain A18. Direct comparison of these strains is not fully justified, due to different metabolic background of these strains.
Obviously even supplementation of the culturing media for the auxotroph with uracil does not fully account for its deficiency. Nevertheless, the observed characteristics of here obtained recombinant strain compares favorably with the literature data, illustrating the strain's biotechnological potential as a multidirectional microbial cell factory.

\section{Biomass growth and glycerol utilization}

Preliminary shake flask cultivations in YPD, YPGly and MMTGly media indicated that the recombinant NCYC3825 strain exhibits higher biomass formation than the parental strain A18 when glycerol was the main carbon source (YPGly and MMTGly media; $\mathrm{p}<0.05, \mathrm{t}$-Student's test) (Figure 6). No significant differences in the biomass yield were observed in YPD medium ( $\mathrm{p}<0.05$, $\mathrm{t}$-Student's test). These results were further verified in bioreactor cultivations with glycerol as the main carbon source. The cultivation was carried out in a fed-batch mode, and the time of feeding of a new medium portion was dictated by glycerol utilization level (Figure 7). Since the recombinant strain grew more rapidly than the parental strain, four portions of the feed were added into the recombinant's culture, while only one portion of the feed was fed into the parental strain's culture, during the same process time. The final biomass yield and productivity were of $42 \mathrm{~g} \mathrm{~L}^{-1}$ and $0.62 \mathrm{~g} \mathrm{~L}^{-1} \mathrm{~h}^{-1}$ for the recombinant strain and $23 \mathrm{~g} \mathrm{~L}^{-1}$ and $0.34 \mathrm{~g} \mathrm{~L}^{-1} \mathrm{~h}^{-1}$ for the parental strain (Table 1). The reason behind increased biomass formation could be attributed to modified red-ox potential caused by DhaT action. According to the literature data, altered balance in reducing equivalents turnover, triggered by either oxidoreductase or $V H b$ gene expression, brought similar macroscopic

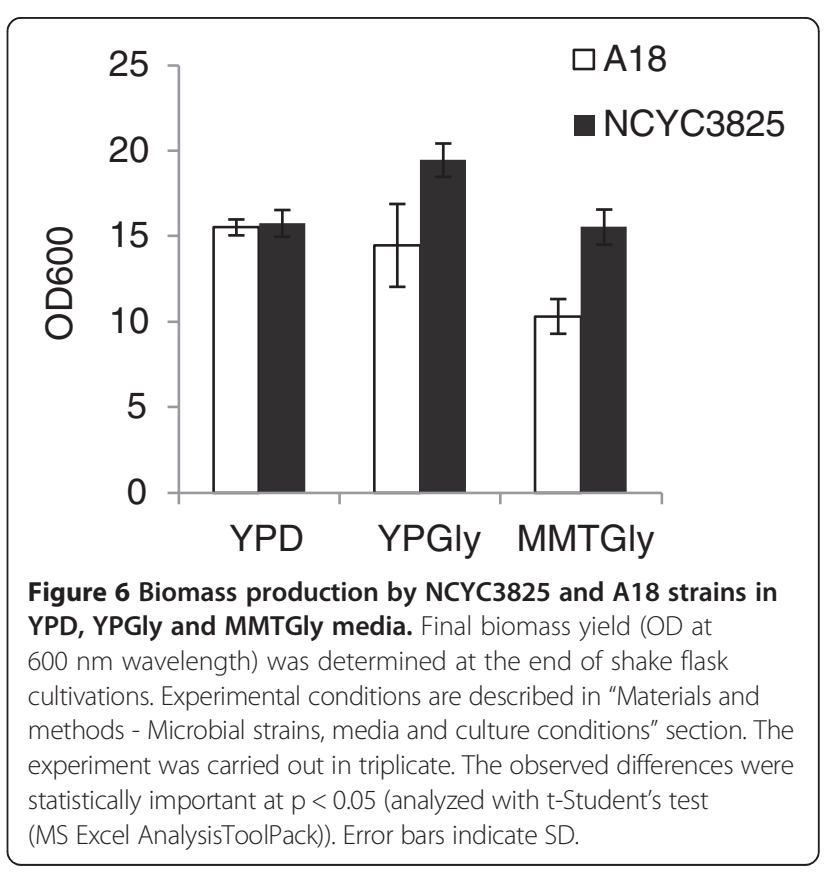




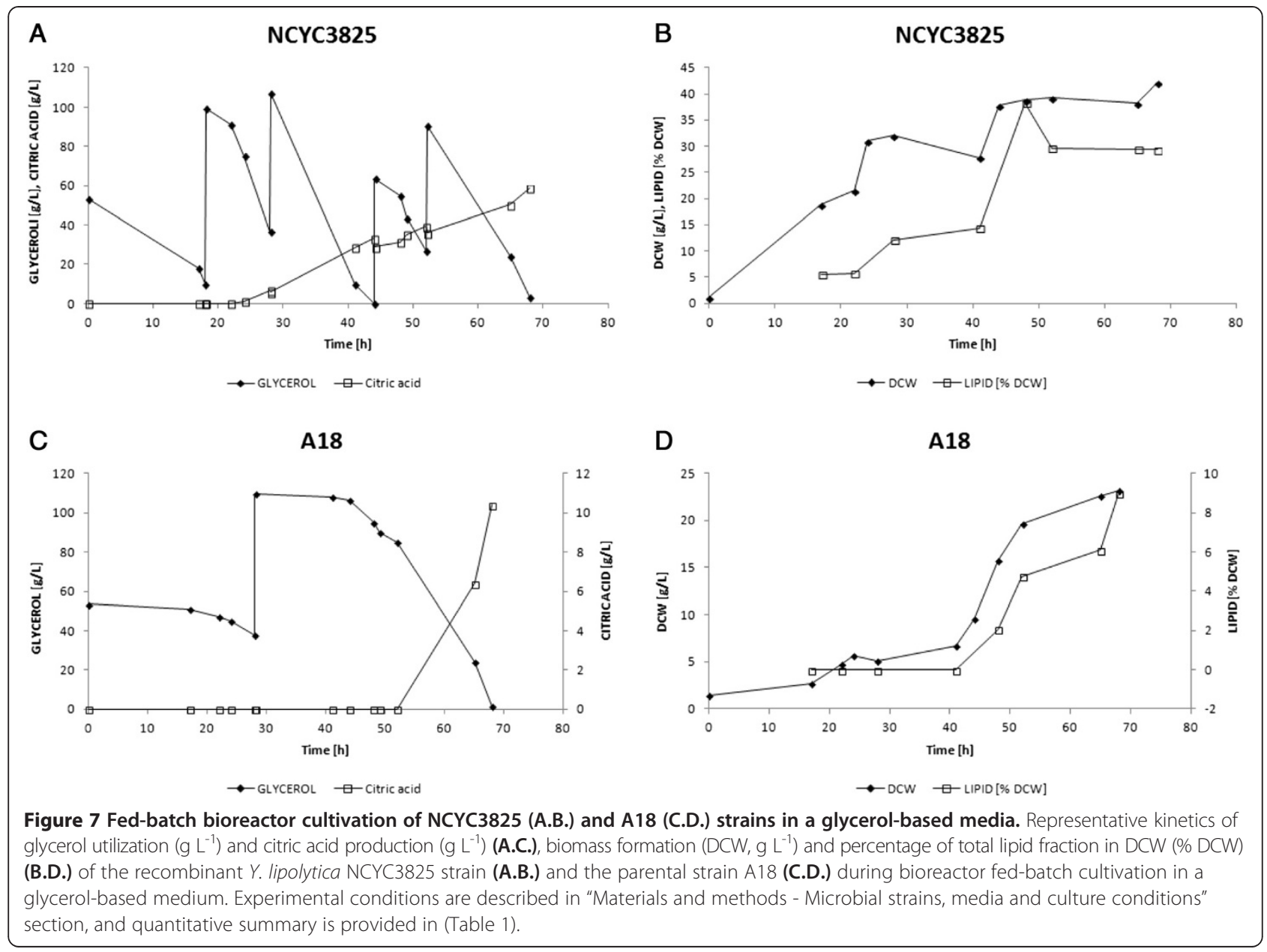

characteristics of the modified yeast strains, marked by i.a. improved biomass formation [58-60].

\section{Production of industrially attractive metabolites}

The final stage of the presented study was metabolic characterization of the obtained recombinant strain, with a particular focus on production of industrially attractive metabolites. To this end, culture supernatants were analyzed by GC/MS and HPLC. Furthermore, since one of the most interesting traits of $Y$. lipolytica is its ability to accumulate high amounts of lipids, cellular lipid content and fatty acid profiles were determined. These analyses are relevant with respect to the ultimate aim of the presented study (modification of glycerol catabolism), since, after entering the cell, glycerol is phosphorylated to G3P which is the second substrate (with acyl-CoA) for TAGs biosynthesis (compare (Figure 1). The level of intracellular G3P was shown to significantly influence TAGs accumulation [34].

The recombinant strain produced considerably higher amounts of citric acid, when compared to the parental strain, reaching respectively: 58.8 vs $10 \mathrm{~g} \mathrm{~L}^{-1}$ of citric acid, with volumetric productivity 0.86 vs $0.15 \mathrm{~g} \mathrm{~L}^{-1} \mathrm{~h}^{-1}$ and yield 0.17 vs $0.07 \mathrm{~g} \mathrm{~g}^{-1}$ (Table 1). The obtained final titer of citric acid constitutes an interesting result compared to the

Table 1 Quantitative comparison of the results obtained in bioreactor fed-batch cultivation in a glycerol-based medium

\begin{tabular}{|c|c|c|c|c|c|c|c|c|c|}
\hline & $\begin{array}{l}\text { DCW } \\
{\left[g^{-1}\right]}\end{array}$ & $\begin{array}{l}\text { DCW } \\
{\left[g^{-1} h^{-1}\right]}\end{array}$ & $\begin{array}{l}\mathrm{CA} \\
{\left[\mathrm{g} \mathrm{L}^{-1}\right]}\end{array}$ & $\begin{array}{l}\text { CA } \\
{\left[g^{-1} h^{-1}\right]}\end{array}$ & $\begin{array}{l}\text { CA } \\
{\left[\mathrm{g} \mathrm{g}_{\mathrm{DCw}}{ }^{-1}\right]}\end{array}$ & $\begin{array}{l}\text { CA } \\
{\left[\text { g g glycerol }^{-1} \text { ] }\right.}\end{array}$ & $\begin{array}{l}\text { LIPIDS } \\
{\left[g^{-1}\right]}\end{array}$ & $\begin{array}{l}\text { LIPIDS } \\
\left.\text { [g g }_{D C w}{ }^{-1}\right]\end{array}$ & $\begin{array}{l}\text { LIPIDS } \\
\text { [g g glycerol }^{-1} \text { ] }\end{array}$ \\
\hline NCYC3825 & 42 & 0.62 & 58.8 & 0.86 & 0.89 & 0.17 & 13 & 0.3 & 0.039 \\
\hline A18 & 23 & 0.34 & 10.4 & 0.15 & 0.32 & 0.08 & 2.98 & 0.09 & 0.024 \\
\hline
\end{tabular}

DCW - dry cellular weight, CA - citric acid, LIPIDS - total lipids. Final titer $\left[\mathrm{g} \mathrm{L}^{-1}\right]$, volumetric productivity $\left[\mathrm{g} \mathrm{L}^{-1} \mathrm{~h}^{-1}\right]$, biomass-normalized titer $\left[\mathrm{g} \mathrm{OD}_{600}{ }^{-1}\right]$ or $\left[\mathrm{g} \mathrm{g}_{\mathrm{DCw}}{ }^{-1}\right.$ ], yield $\left[\mathrm{g} \mathrm{g}_{\text {glycerol }}{ }^{-1}\right.$ ]. Statistical importance of the observed differences was analyzed with t-Student's test (MS Excel AnalysisToolPack) - the observed differences were statistically important at $\mathrm{p}<0.05$. For kinetics presentation see (Figure 7). 
literature data, but obviously requiring further optimization. One of the earliest paper on glycerol bioconversion into citric acid using $Y$. lipolytica reported the final titer of citric acid reaching $35 \mathrm{~g} \mathrm{~L}^{-1}$ [61]. Further studies brought successive improvement up to $62.5 \mathrm{~g} \mathrm{~L}^{-1}$ in flask cultures during $600 \mathrm{~h}$ [11]. Most recently, advanced cultivation approaches and/or selection of mutagenized strains regarding the ability to produce higher titers of citric acid lead to outstanding achievements. Repeated batch cultivation allowed for improvement of citric acid final titers from $112 \mathrm{~g} \mathrm{~L}^{-1}$ to $124 \mathrm{~g} \mathrm{~L}^{-1}$ [9] when A-101-1.22 strain was grown in a waste glycerol-based medium. In another paper by the same research team, strains $Y$. lipolytica Wratislavia AWG7 and Wratislavia 1.31 produced up to $157.5 \mathrm{~g} \mathrm{~L}^{-1}$ of citric acid in a fed-batch culture from waste glycerol [62]. N1 mutant strain, generated through random chemical mutagenesis, produced $217 \mathrm{~g} \mathrm{~L}^{-1}$ of citric acid when grown on petrolatum, and $120 \mathrm{~g} \mathrm{~L}^{-1}$ of citric acid when ethanol was used as a carbon source [15]. Another mutant strain by this research team, $Y$. lipolytica $\mathrm{N} 15$, was tested in media containing pure and waste glycerol, producing 98 and $71 \mathrm{~g} \mathrm{~L}^{-1}$ of citric acid, respectively [10].

Analysis of the lipid content in NCYC3825 and A18 cells grown in a glycerol-based medium showed superior ability of the former strain to accumulate significant amounts of lipids under applied culturing conditions (Figure 7). The ultimate values of lipid content in the culture and the percentage of lipid fraction in DCW at the end of culturing reached 13 vs $3 \mathrm{~g} \mathrm{~L}^{-1}$ and $29.3 \%$ (with a peak value of nearly $40 \%$ of total lipid content in DCW) vs $9.03 \%$ for the recombinant and the parental strain, respectively. Interpretation of these results should be carried out while bearing in mind that growth of some $Y$. lipolytica strains in glycerol-based media is divided into three growth phases: biomass formation, lipid accumulation and citric acid production $[12,63]$. Then, it becomes obvious that the principal trait of the recombinant strain distinguishing it from the parental strain is its faster growth. The observed higher accumulation of lipids and higher titers of citric acid are related to earlier entering "lipogenic" and subsequent switching to "citric acid production" phases. In [63] it has been postulated that lipid turnover, concomitant with entering citric acid production phase, is related to reduced activity of glycerol kinase in the stationary phase of growth, when the glycerol uptake rate is reduced and its intracellular concentration is low. Then, storage lipids are mobilized and used for maintenance purposes.

The results obtained in the presented study with NCYC3825 strain concerning lipid synthesis per $g$ of DCW ( 40\% of DCW) are comparable with the best values found in the literature, while the final titer of lipids per culture volume $\left(13 \mathrm{~g} \mathrm{~L}^{-1}\right)$ represents one of the best results reported to date. Corresponding results with respect to lipid fraction in DCW were obtained with Y. lipolytica ACA-YC 5033 strain $\left(2 \mathrm{~g} \mathrm{~L}^{-1}, 30 \%\right.$ of DCW, even though the culture was carried out in shake flasks) [64] and Y. lipolytica LGAM S(7)1 (3.5 $\mathrm{g} \mathrm{L}^{-1}, 43 \%$ of DCW) when cultured in continuous mode on rawglycerol-based medium [8]. 30\% of DCW was represented by lipids in Y. lipolytica N15 mutant grown on crude glycerol during a biomass formation phase $\left(\sim 6 \mathrm{~g} \mathrm{~L}^{-1}\right)$, with a sharp decrease in lipid content after entering citric acid production phase [10]. Repeated batch mode cultivation in pure-glycerol-based medium allowed for maximal storage lipid accumulation reaching over $20 \%$ of DCW $\left(1.3 \mathrm{~g} \mathrm{~L}^{-1}\right)$ in $Y$. lipolytica ACA-DC 50109 cells, followed by a nearly two-fold decrease in the subsequent growth phase [63]. The observed high lipid fraction in Y. lipolytica NCYC3825 could be attributed to fast growth rate concomitant with prolonged growth phase due to fed-batch mode of cultivation, which is one of the strategies aiming at improvement of microbial oil production. Different strategy towards increasing storage lipid accumulation was applied and described in [65], where after carbon source exhaustion and reaching stationary phase of growth, acetic acid was added into the culture, as a substrate for bioconversion into lipids. Such approach lead to accumulation of lipids at $40 \%$ of DCW. The highest level of de novo synthesized lipids from non-hydrophobic substrate was obtained by genetically engineered strain, which accumulated $41.4 \%$ of DCW as lipids in shake flask cultivations, and $61.7 \%$ of $\mathrm{DCW}$ in bioreactor cultivation $(120 \mathrm{~h})$ on glucose [33]. The engineered strain was modified trough co-expression of two genes involved in triacylglycerols (TAGs) biosynthesis - diacylglycerol acyltransferase (DGA1) and acetyl-CoA carboxylase (ACC1), the final and the first activity of the pathway (see Figure 1). Such approach, increased rate of the first ("push" the carbon flux) and the last ("pull" the carbon flux) reactions of the lipid synthesis pathway, leading to higher total lipid accumulation per $\mathrm{g}$ of DCW.

Ex novo storage lipid accumulation reached $54 \%$ and $33 \%$ of DCW when Y. lipolytica was grown in a batch mode on industrial fat as the sole carbon source and on a mixture of industrial fat and glycerol, respectively $[22,66]$. In [23], relatively high accumulation of intracellular lipid was reported, when Y. lipolytica ACA-DC 50109 was grown in the presence of solid industrial derivative of tallow in shake flasks (53\% of DCW), and lower, when the culture was carried out in the bioreactor (up to $16 \%$ of DCW). The authors suggested that such a discrepancy between slightly aerated flask cultures and highly aerated bioreactor cultures triggers differences in activity of acyl-CoA oxidases, higher at greater oxygen provision. Considering this statement, the results obtained with the NCYC3825 strain are particularly interesting, as such high level $\left(40 \%\right.$ and $\left.13 \mathrm{~g} \mathrm{~L}^{-1}\right)$ of lipid 
synthesis was achieved in highly aerated and stirred culture. On the other hand, the report [33] indicated the opposite trend - higher lipid accumulation was observed in the bioreactor culture. The highest value of ex novo storage lipid accumulation, $70 \%$ of DCW, was reported for genetically engineered strain lacking G3P dh activity (Agut2; higher provision of G3P for lipid synthesis) cultured in the presence of ultrapure oleic acid [13]. In the same report a "double" knock-out recombinant strain ( $\triangle$ gut $2 \Delta p o x 1-6=$ lack of unproductive G3P dissipation and lack of stored lipid mobilization) was characterized. The strain accumulated $13 \%$ and $42 \%$ of its DCW as lipid, when grown in glucose- and oleic acid-based medium, respectively. This comparison illustrates the strain's potentialities in de novo and ex novo lipid accumulation, with significant advantage of the latter. Comparable results regarding ex novo lipid synthesis were reported for genetically engineered strains over-expressing GPD1 gene in $\Delta$ pox1-6 and $\Delta g u t 2 \Delta p o x 1-6$ background, accumulating $65 \%$ and $70 \%$ of DCW as lipid, respectively, when grown in oleic acid-based medium [34].

Recently, successful metabolic engineering approaches towards modification of fatty acid composition in $Y$. lipolytica have been reported. Metabolic engineering strategy allowed development of Y. lipolytica strain producing eicosapentaenoic acid at high level [67] or increased accumulation of conjugated linoleic acid, known for its salutary properties [68]. Fatty acid composition analyses (Table 2) of the total lipid fraction in NCYC3825 and A18 cells at the end of bioreactor cultivation (Figure 7) showed that oleic acid was the main component of lipids, followed by palmitic and linoleic acids, which is commonly observed in various oleaginous fungi [for comprehensive study on fatty acid profile in oleaginous fungi see [69]). As postulated here, NCYC3825 and A18 cells were at different metabolic phase at the time of sample collection. While NCYC3825 already entered citric acid production phase, A18 cells were at late biomass formation phase. Therefore, A18 total lipid samples could represent characteristic profile of fatty acids at the onset of lipogenesis, while NCYC3825 samples, could serve as representative samples of citric acid production phase, since no direct modification of glycerolipids turnover was introduced to the recombinant strain. The most significant change in fatty acid profile between the two samples is abrupt drop (by nearly 10\%) in oleic acid abundance in NCYC3825 cells. These results greatly correspond with those by [63], where significant decrease in oleic acid contribution to the total lipid fraction was observed for Y. lipolytica cells after entering citric acid production phase. Such observation may suggest that this fatty acid is rapidly mobilized from storage lipids along with entering citric acid production phase.
Table 2 Fatty acid composition profiles at the end of bioreactor cultivation in glycerol-based media

\begin{tabular}{lcc}
\hline Fatty acid & A18 & NCYC3825 \\
\hline Myristic acid (C14:0) & 0,30 & 0,21 \\
Pentadecanoic acid (C15:0) & 0,24 & 0,41 \\
Palmitic acid (C16:0) & 12,56 & 15,38 \\
Palmitoleic acid (C16:1n9) & 0,77 & 2,79 \\
Palmitoleic acid (C16:1n7) & 9,86 & 11,10 \\
Heptadecanoic acid (C17:0) & 0,14 & 0,17 \\
cis-10-Heptadecanoic acid (C17:1) & 0,84 & 0,82 \\
Stearic acid (C18:0) & 4,54 & 4,20 \\
Oleic acid (C18: 1n9C) & 47,48 & 38,88 \\
Oleic acid (C18: 1c11) & 1,64 & 1,92 \\
Oleic acid (C18:1c15) & 0,08 & 0,26 \\
Linoleic acid (C18:2n6C) & 13,26 & 14,58 \\
Linoleic acid (C18:2c9c15) & 5,79 & 7,50 \\
a-Linolenic acid (18:3 n3) & 0,31 & 0,59 \\
Behenic acid (C22:0) & 0,00 & 0,07 \\
Erucic acid (C22:1n9) & 0,25 & 0,22 \\
Arachidonic acid (C20:4n6) & 0,00 & 0,03 \\
cis-13,16-Docosadienoic acid (C22:2) & 0,08 & 0,02 \\
cis-5,8,11,14,17-Eicosapentanoic acid (C20:5n3) & 1,89 & 0,85 \\
Total of fatty acids: Saturated & 17,76 & 20,44 \\
Total of fatty acids: Monounsaturated & 60,91 & 55,98 \\
Total of fatty acids: Polyunsaturated & 21,32 & 23,57 \\
\hline
\end{tabular}

The numbers provide mean percentage content of total lipid fraction represented by the respective fatty acid. The analyses were carried out in duplicate.

Finally, GC/MS analysis of culture supernatants showed that the novel recombinant strain NCYC3825 produces considerable amounts of 2-phenylethanol (2-PE), which is a valuable aroma compound (US\$ 1000 per $\mathrm{kg}$ ), widely used in food and cosmetics production. The ability to produce 2-PE by $Y$. lipolytica strains, has not been described for $Y$. lipolytica species previously (for more details on 2-PE production by $Y$. lipolytica please refer to [70]). The recombinant strain produced significantly higher titers of 2-PE than the parental strain $\left(1 \mathrm{~g} \mathrm{~L}^{-1}\right.$ vs $320 \mathrm{mg} \mathrm{L}^{-1}$; statistical importance at $\mathrm{p}<0.05$, t-Student's test) under applied conditions - in shake flask cultivation with glycerol as a carbon source (Figure 8, Table 3). The exact course of the 2-PE biosynthesis pathway in $Y$. lipolytica remains to be elucidated, however, it appears that it follows the general routes of L-Phe bioconversion (Ehrlich pathway), as supplementation with this amino acid strongly increases 2-PE production.

With respect to the genetic modification introduced to NCYC3825 strain, an increase in 2-PE biosynthesis can be primarily attributed to faster growth of the recombinant strain (greater biomass production), which is perfectly 

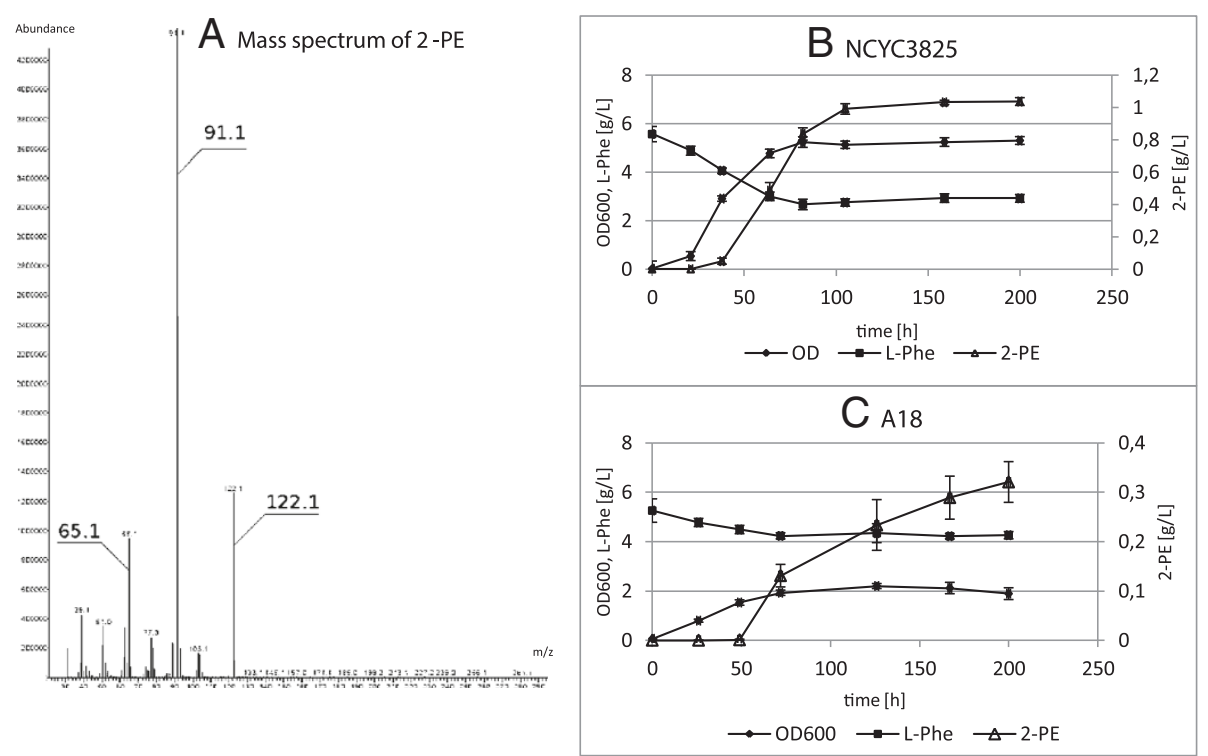

Figure 8 2-Phenylethanol production by NCYC3825 and A18 strains in a glycerol-based medium. A. Mass spectrum of 2-PE which allowed identification of the compound, obtained after GC/MS analysis. (B. NCYC3825, C. A18) Kinetics of 2-Phenylethanol production, L-Phenylalanine utilization and biomass formation (OD at $600 \mathrm{~nm}$ wavelength) during shake flask cultivations in a glycerol-based medium. Experimental conditions are described in "Materials and methods - Microbial strains, media and culture conditions" section, and quantitative summary is provided in (Table 3). The experiment was carried out in triplicate. Error bars indicate SD.

illustrated by the biomass-normalized productivity parameter, 0.19 vs 0.17 [g OD 600 ] for the recombinant and the parental strain, respectively (lack of difference in this parameter between the two strains was confirmed by $\mathrm{t}$-Student's test at $\mathrm{p}<0.05)$. 2 -PE production in the yeast cells is predominantly a bioconversion process (L-Phe converted into 2-PE), and contribution of de novo synthesis, through the shikimate pathway, is rather negligible [71]. Therefore, the more cells per volume, the more "catalyst" per volume, leading to higher titers of the product. Another, less probable, hypothesis explaining superior production of 2-PE by the NCYC3825 strain could be higher provision of reducing equivalents obtained in the recombinant cells, which are required for the final reaction of 2-PE formation. The enzymatic activity of phenylacetaldehyde dehydrogenase (PhAcAld dh), catalyzing the final reduction step in the 2-PE formation, has not been identified to date. For the other yeast species PhAcAld dh has been postulated to be NADH-dependent alcohol dehydrogenase. Assuming PhAcAld dh being the bottleneck of the 2-PE formation, significant increase in oxidoreductase activity providing higher abundance of reducing equivalents could importantly contribute to an increase in 2-PE synthesis. However, these considerations remain highly hypothetical and implausible.

\section{Conclusions}

In this study we attempted modification of glycerol catabolism in Yarrowia lipolytica strain through genetic engineering approach. To this end, we designed and constructed a novel integrative expression vector bearing three heterologous genes, natively involved in glycerol metabolism and controlled in glycerol-induced manner by G3P dh promoter. We proved that the vector can be stably integrated with the host genome in operational

Table 3 Quantitative comparison of cultivation parameters obtained in shake flask cultivations aiming at 2-PE production

\begin{tabular}{|c|c|c|c|c|c|c|}
\hline & $\begin{array}{l}\text { 2-PE } \\
{\left[\mathrm{mg} \mathrm{L}^{-1}\right]}\end{array}$ & $\begin{array}{l}\text { 2-PE } \\
{\left[\mathrm{mg} \mathrm{L}^{-1} h^{-1}\right]}\end{array}$ & $\begin{array}{l}\text { Utilized L-Phe } \\
{\left[\mathrm{g} \mathrm{L}^{-1}\right]}\end{array}$ & $\begin{array}{l}\text { 2-PE/L-Phe } \\
{\left[g_{\text {2-PE }} \text { gL-Phe }^{-1}\right]}\end{array}$ & $\begin{array}{l}\text { 2-PE/biomass } \\
{\left[\mathrm{g} \mathrm{OD}_{600}{ }^{-1}\right]}\end{array}$ & $\begin{array}{l}O D_{600} \\
{\left[O D_{600} \text { units }\right]}\end{array}$ \\
\hline NCYC3825 & 1056.0 & 4.7 & 2.57 & 0.41 & 0.19 & 5.29 \\
\hline A18 & 320.6 & 1.68 & 0.99 & 0.32 & 0.17 & 1.88 \\
\hline
\end{tabular}

Final titer $\left[\mathrm{mg} \mathrm{L}^{-1}\right]$, volumetric productivity $\left[\mathrm{mg} \mathrm{L}^{-1} \mathrm{~h}^{-1}\right]$, utilized L-Phe $\left[\mathrm{g} \mathrm{L}^{-1}\right]$, yield 2-PE from L-Phe $\left[\mathrm{g}_{2-\mathrm{PE}} \mathrm{gL}_{\mathrm{L}-\mathrm{Phe}}{ }^{-1}\right]$, biomass normalized 2-PE titer 2-PE/biomass $\left[\mathrm{g} \mathrm{OD}_{600}{ }^{-1}\right]$, biomass production expressed as turbidity at $600 \mathrm{~nm}$ wavelength $\left[\mathrm{OD}_{600}\right.$ units]. Experiments were carried out in triplicate. Statistical importance of the observed difference was analyzed with t-Student's test (MS Excel AnalysisToolPack) - the observed differences were statistically important at $\mathrm{p}<0.05$. For kinetics presentation see (Figure 8). 
manner. Expression of wide-spectrum alcohol oxidoreductase was driven at high level, while expression of clostridial genes was maintained at lower level. Here obtained recombinant strain was characterized by several interesting traits: relatively high biomass formation $\left(42 \mathrm{~g} \mathrm{~L}^{-1}\right)$ and lipids accumulation (peak value $38 \%_{\text {LIPIDS }}$ of DCW), production of citric acid $\left(58 \mathrm{~g} \mathrm{~L}^{-1}\right)$ and 2-phenylethanol $\left(1 \mathrm{~g} \mathrm{~L}^{-1}\right)$ in glycerol-based media. Due to heterogeneous nature of the observed alterations, we postulated that the main driving force of the modified phenotype was faster growth of the recombinant strain, triggered by modification in the red-ox potential. Our results demonstrate the potential multidirectional use of a novel Yarrowia lipolytica strain as a microbial cell factory.

\section{Materials and methods}

\section{Microbial strains, media and culture conditions}

Y. lipolytica A18 and A10 strains used in this study were kindly donated by Prof. M. Robak from Department of Biotechnology and Food Microbiology, Wroclaw University of Environmental and Life Sciences, Poland. S. blattae and $C$. butyricum strains were purchased from ATCC and DSMZ collections, respectively, and were handled according to the protocol provided by the supplier. The obtained recombinant strain, $Y$. lipolytica NCYC3825, has been deposited for a patent purpose in the National Collection of Yeast Cultures (Norwich, UK). Strains used in this study are summarized in (Table 4).

Routine laboratory cultivation of E. coli JM109 parental strain, as well as all the following transformants was carried out according to the standard laboratory procedures [72]. Typically E. coli strains were cultured in LB medium, containing (per liter): glucose 10 g, Bacto Peptone $10 \mathrm{~g}$, yeast extract $5 \mathrm{~g}$. For transformants cultivation ampicilin was added (at $100 \mathrm{mg} \mathrm{L}^{-1}$ ) to maintain selective pressure. Y. lipolytica A18, A10, and the obtained recombinant NCYC3825 strains were cultured in YPD or MMT and maintained according to the protocols described in [28]. Typically the yeast strains were cultured at $30^{\circ} \mathrm{C}$, $250 \mathrm{rpm}$ on a rotary shaker in YPD medium, containing per liter: Bacto Peptone 20 g, yeast extract 10 g, glucose $20 \mathrm{~g}$. Alternatively yeast strains were routinely cultured in MMT medium, containing per liter: $\mathrm{NH}_{4} \mathrm{H}_{2} \mathrm{PO}_{4} 5 \mathrm{~g}$, $\mathrm{KH}_{2} \mathrm{PO}_{4} 2.5 \mathrm{~g}, \mathrm{MgSO}_{4} \times 7 \mathrm{H}_{2} \mathrm{O} 1 \mathrm{~g}$, glucose $10 \mathrm{~g}$, thiamine $3 \mathrm{mg}$, trace elements solution II $1.0 \mathrm{~mL}$ per liter of deionized water. Minimal media for the parental auxotroph strain were supplemented with uracil at $2 \mathrm{mg} \mathrm{L}^{-1}$.

Preliminary cultivation tests were carried out in shake flasks in total culture volume of $20 \mathrm{~mL}$. Rich (YPD) medium was prepared as described in the preceding paragraph. YPGly was prepared as follows: Bacto Peptone $20 \mathrm{~g}$, yeast extract $10 \mathrm{~g}$, glycerol $20 \mathrm{~mL}$ per liter of deionized water. MMTGly, modified by substitution of glucose with glycerol, [28] contained: $\mathrm{NH}_{4} \mathrm{H}_{2} \mathrm{PO}_{4} 5 \mathrm{~g}, \mathrm{KH}_{2} \mathrm{PO}_{4}$
$2.5 \mathrm{~g}, \mathrm{MgSO}_{4} \times 7 \mathrm{H}_{2} \mathrm{O} 1 \mathrm{~g}$, glycerol $10 \mathrm{~g}$, thiamine $3 \mathrm{mg}$, trace elements solution II $1.0 \mathrm{~mL}$ per liter of deionized water. Cultures of the parental and the recombinant strains were carried out in triplicate, at $30^{\circ} \mathrm{C}$, with shaking at $250 \mathrm{rpm}$.

Shake flask cultivations of NCYC3825 and A18 yeast strains aiming at 2-PE production from L-Phe was carried out in glycerol-based medium, containing per liter: glycerol $50 \mathrm{~g}, \mathrm{KH}_{2} \mathrm{PO}_{4} 15 \mathrm{~g}, \mathrm{MgSO}_{4} \mathrm{x} 7 \mathrm{H}_{2} \mathrm{O} 0.5 \mathrm{~g}$, Yeast Nitrogen Base $0.2 \mathrm{~g}$, L-phenylalanine $5 \mathrm{~g}$, trace elements solution II $1.0 \mathrm{~mL}$, thiamine $3 \mathrm{mg}$. Cultures of the parental and the recombinant strains were carried out in triplicate, at $30^{\circ} \mathrm{C}$, with shaking at $250 \mathrm{rpm}$. Time point samples were stored at $-20^{\circ} \mathrm{C}$ for subsequent liquid analysis (HPLC) and biomass growth determination $\left(\mathrm{OD}_{600}\right)$.

Bioreactor cultivations were carried out in BIOSTAT ${ }^{\circ}$ A plus (Sartorius) stirred-tank bioreactors, total volume of $5 \mathrm{~L}$, culture medium volume of $2 \mathrm{~L}$. Culture medium was inoculated with $10 \%(\mathrm{v} / \mathrm{v}) 48 \mathrm{~h}$ YPD culture. $\mathrm{pH}$ and temperature were automatically adjusted to 4.0 and $30^{\circ}$ C. Stirring and aeration were automatically adjusted to maintain oxygen saturation of the culture at 30\%. Culture parameters were automatically monitored with BioPAT MFCS SCADA. Fed-batch culture aiming at maximization of biomass formation was carried out in medium containing: glycerol $40 \mathrm{~mL},\left(\mathrm{NH}_{4}\right)_{2} \mathrm{SO}_{4} 6 \mathrm{~g}, \mathrm{KH}_{2} \mathrm{PO}_{4} 1.1 \mathrm{~g}$, $\mathrm{MgSO}_{4} \times 7 \mathrm{H}_{2} \mathrm{O} 0.14 \mathrm{~g}$, yeast extract $10 \mathrm{~g}$, Bacto pepton $0.5 \mathrm{~g}$, trace elements solution II $1.0 \mathrm{~mL}$, AntiFoam 204 (Sigma-Aldrich) $0.5 \mathrm{~mL}$ per liter of deionized water (plus external supplementation with AntiFoam 204 during cultivation). The bioreactor volume was completed with $0.5 \mathrm{~kg}$ of the feed medium, containing: glycerol $390 \mathrm{~mL}$, $\left(\mathrm{NH}_{4}\right)_{2} \mathrm{SO}_{4} 60 \mathrm{~g}$, yeast extract $10 \mathrm{~g}$ per liter of deionized water; dosing of the feed depended on the measured glycerol concentration in the culture. Time point samples were stored at $-20^{\circ} \mathrm{C}$ for subsequent liquid analysis (HPLC) and biomass growth determination (gravimetrically).

\section{Molecular biology tools and protocols Competent cells and transformation}

Preparation of $E$. coli $\mathrm{CaCl}_{2} / \mathrm{MgCl}_{2}$ competent cells and heat-shock transformation were carried out according to the standard molecular biology protocols [72]. Preparation of $Y$. lipolytica A18 competent cells and transformation via a lithium acetate procedure were completed according to [28] protocols, and stocks of the prepared competent cells were liquid nitrogen-frozen and stored at $-80^{\circ} \mathrm{C}$. Before transformation, the competent cells were thawed on ice and washed twice in lithium acetate buffer, according to the applied protocol.

\section{DNA manipulations}

Standard molecular biology techniques were used throughout this study [72]. Vectors used in this study are 
Table 4 Microbial strains and vectors used in this study

\begin{tabular}{|c|c|c|}
\hline \multirow{2}{*}{$\begin{array}{l}\text { Strain } \\
\text { Yarrowia lipolytica A18 }\end{array}$} & \multicolumn{2}{|l|}{ Relevant characteristics and application } \\
\hline & ura3-suc2+ & Host strain \\
\hline Yarrowia lipolytica A10 & wild type & $\begin{array}{l}\text { Natural isolate, donor of regulatory elements } \\
\text { for expression cassette }\end{array}$ \\
\hline Clostridium butyricum DSM10702 & wild type & Donor of $d h a B 1$ and $d h a B 2$ genes sequences \\
\hline Shimwellia blattae ATCC334030 & wild type & Donor of a dhaT gene sequence \\
\hline Escherichia coli JM109 & 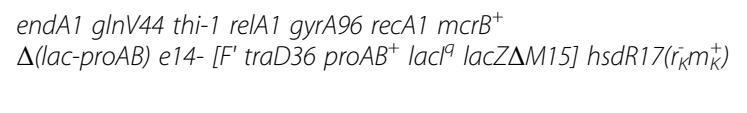 & $\begin{array}{l}\text { Laboratory strain used as a host for routine } \\
\text { cloning of pGEM-T-Easy constructs and } \\
\text { intermediate constructs of the final vector }\end{array}$ \\
\hline Yarrowia lipolytica NCYC 3825 & $\Delta u r a 3+$ suc2 + dhaB1 + dhaB2 +dhaT+ & $\begin{array}{l}\text { The recombinant strain obtained in this work, } \\
\text { deposited in NCYC, Norwich, UK }\end{array}$ \\
\hline \multicolumn{3}{|l|}{ vectors and genetic constructs } \\
\hline pGEM-T-Easy/Promega & \multicolumn{2}{|l|}{ T/A amplicons cloning } \\
\hline pBR322/Life Technologies & \multicolumn{2}{|l|}{ donor of ori and $\beta$-lactamase } \\
\hline pV1/this work & \multicolumn{2}{|l|}{ pBR322-based construction platform, circularized with linker 1} \\
\hline pV2/this work & \multicolumn{2}{|l|}{ pBR322-based construction platform, circularized with linker 2} \\
\hline pV1-dhaT/this work & \multicolumn{2}{|c|}{ EcoRI/Xbal_PROM G3Pdh I--Sall-dhaT_Sacl-TER XPR2-like I--Xbal-ampr-ori- } \\
\hline pV1-dhaB1/this work & \multicolumn{2}{|c|}{ ECORI/MIul-PROM G3Pdh 2--Sall-dhaB1-Bglll-TER XPR2-like 2--Mlul - ampr-ori- } \\
\hline pV2-dhaB2/ura3d/this work & \multicolumn{2}{|c|}{ Kpnl-PROM G3Pdh 3-BamHI-dhaB2-ECoRV-TER XPR2-like 3-Xbal-Pvull-ura3-Notl-ampr-ori- } \\
\hline pYLG1/this work & \multicolumn{2}{|c|}{$\begin{array}{l}\text { Kpnl-PROM G3Pdh 3-BamHI-dhaB2-ECORV-TER XPR2-like 3-Xbal--PROM G3Pdh I--Sall-dhaT- } \\
\text { Sacl-TER XPR2-like I--Xbal-Mlul--PROM G3Pdh 2--Sall-dhaB1-Bglll-TER XPR2-like 2--Mlul } \\
\text { Pvull-ura3-Notl-amp-ori- }\end{array}$} \\
\hline Expression cassette/this work & \multicolumn{2}{|c|}{$\begin{array}{l}\text { rDNA R-KpnI-PROM G3Pdh 3-BamHI-dhaB2-ECoRV-TER XPR2-like 3-Xbal--PROM G3Pdh I--Sall- } \\
\text { dhaT-Sacl-TER XPR2-like I--Xbal-Mlul--PROM G3Pdh 2--Sall-dhaB1-Bglll- } \\
\text { TER XPR2-like 2--Mlul Pvull-ura3-Notl-rDNA L }\end{array}$} \\
\hline
\end{tabular}

summarized in (Table 4). Primers and linkers used in this study are listed in Additional file 1. Restriction enzymes, polynucleotide kinase T4, shrimp-alkaline phosphatase and DNA molecular markers for electrophoresis were all purchased from Thermo Fisher Scientific Inc. (Walthman, MA). DNA T4 ligase was obtained from New England Biolabs (Ipswich, MA). DNA Taq polymerases were purchased from Qiagen (Valencia, CA) and A\&A Biotechnology (Gdynia, Poland). PCR reactions were set up in a Veriti $^{\oplus}$ ThermalCycler (Applied Biosystems). PCR was used as a method of obtaining of the final vector construction elements, selecting yeast and bacterial clones, verifying the intermediate constructs completeness, assessing the expression cassette stability. All enzymatic reactions were set up according to the manufacturers' protocols. All the following steps were conducted with the use of appropriate kit form A\&A Biotechnology (Gdynia, Poland): genomic DNA isolation from yeast (Genomic Mini AX yeast kit) and bacterial cells (Genomic Mini kit), PCR products and DNA fragments purification (Clean Up kit), DNA plasmid isolation in small and medium scale (Plasmid Mini kit and Plasmid Midi kit), DNA fragments purification from agarose gel (Gel Out kit).

Schematic representation of the subsequent steps of the expression cassette construction is depicted in (Figure 2).
In silico design of the genetic construct was preceded with bioinformatic analysis of each DNA sequence element. Due to complexity of the final construct (pYLG1) and resulting lack of unique endonuclease recognition sites, three intermediate constructs were designed (pV1-dhaT, pV1-dhaB2, pV2-dhaB2/ura3). Moreover, introduction of sequences directing the expression cassette integration into a locus of the $28 \mathrm{~S}$ rDNA gene had to be carried out ex vivo, due to the same reason. A $2.2 \mathrm{~kb}$ fragment of pBR322 vector, containing ori and $\beta$-lactamase gene, was used as a platform for construction of the intermediate constructs. The pBR322 fragment was circularized with one of the two linkers, synthesized in vitro, containing multiple cloning sites in two restriction variants (see Additional file 1). Followingly, each of the DNA fragments coding for heterologous genes dhaB1 [GenBank: AAM54728], dhaB2 [GenBank: AAM54729], dhaT [GenBank: AAX12915], ura3d [GenBank: YLU40564] with 40 nt upstream and $450 \mathrm{nt}$ downstream fragments, glycerolinduced promoter [GenBank: AJ250328.1] with the first intron, and $150 \mathrm{nt}$ fragment of XPR2-like terminator [GenBank: XM502349] were PCR amplified on the appropriate DNA template. Amplicons were cloned into pGEM-T-Easy (Promega Corporation, MA) vector, and analyzed by endonuclease digestion and sequencing. Subsequently, all pGEM-T-Easy constructs were 
endonuclease digested, electrophoretically purified and resulting fragments were sequentially cloned into one of the two pBR322-based constructs. As a result, three intermediate vectors were obtained (pV1-dhaT, pV1-dhaB2, $\mathrm{pV} 2$-dhaB2/ura3). Their completeness and appropriate orientation of the elements after each cloning were confirmed by PCR and endonuclease digestion. The intermediate vector in each case was composed of two parts: bacterial, containing ori and $\beta$-lactamase gene, and expression cassette, containing one heterologous gene flanked with regulatory sequences. The intermediate vector $\mathrm{pV} 2$ dhaB2/ura3d additionally contained sequence encoding a selective marker gene $u r a 3 d$, with a truncated fragment of promoter. In the next step, intermediate vectors pV1dhaT and pV1-dhaB1 were endonuclease digested to separate expression cassettes from the bacterial part of the vector. Expression cassettes of the intermediate vectors pV1-dhaT and pV1-dhaB1 were sequentially cloned into an endonuclease digested and dephosphorylated intermediate vector $\mathrm{pV} 2$-dhaB2/ura3d. As a result, the final vector pYLG1 was generated. Its completeness and proper orientation of all the elements were verified by PCR amplification and endonuclease digestion. In the next step, the final vector pYLG1 was endonuclease digested in order to separate the expression cassette from the bacterial part. After electrophoresis and purification, the resultant expression cassette was flanked with two sequences complementary to a $28 \mathrm{~S}$ rDNA gene sequence. As mentioned above, this step was completed ex vivo. After phosphorylation and purification, the expression cassette was used for the transformation of competent cells of Y. lipolytica A18.

\section{Nucleotide sequence analyses - tools and databases}

DNA sequences of the heterologous genes, the marker gene and the regulatory sequences were obtained from Genolevures (http://www.genolevures.org) and NCBI (http://www. ncbi.nlm.nih.gov/). Sequences were analyzed in BioEdit package (Tom Hall, Ibis Bioscience) and REviewer@ (http:// www.fermentas.com/reviewer/app). PCR primers were designed using OligoCalc tool (http://www.basic.northwestern.edu/biotools/oligocalc.html). DNA sequences after sequencing were analyzed with FinchTV (http://www.geospiza.com/Products/finchtv.shtml) and BLAST tool (blastn and blastx) (http://blast.ncbi.nlm.nih.gov/Blast.cgi).

\section{RNA isolation and transcript quantification - expression analysis and copy number estimation}

RNA from $Y$. lipolytica parental (A18) and recombinant (NCYC3825) strains was isolated according to the protocol provided with Trizol reagent (Life Technologies) after disruption of the yeast cells with glass beads (Sigma-Aldrich) in a Retsch mixer mill (Retsch $\mathrm{GmbH}$, Germany). RNA quantity and quality was analyzed through FA electrophoresis according to [72]. Genomic DNA was eliminated from the samples with DNaseI (Life Technologies). Reverse transcription of RNA to cDNA was carried out with SuperScript III First-Strand Synthesis System for RT-PCR (Life Technologies). Real-time quantitative PCR was carried out with a Real-Time 2xPCR Master Mix SYBR kit A (A\&A Biotechnology). Reactions were set up according to the manufacturer's protocol in Applied Biosystems 7500 apparatus. Real-time PCR primers were designed with Primer Expert Software (Applied Biosystems). The following temperature profile was applied: $94^{\circ}$ C $5 \mathrm{~min},\left(94^{\circ} \mathrm{C} 30 \mathrm{sec}\right.$, annealing temperature according to Primer Expert $\left.15 \mathrm{sec}, 72^{\circ} \mathrm{C}-45 \mathrm{sec}\right) \rightarrow 40 \mathrm{x}, 72^{\circ} \mathrm{C}$ $5 \mathrm{~min}$, Melt Curve: $94^{\circ} \mathrm{C} 15 \mathrm{sec}, 60^{\circ} \mathrm{C} 60 \mathrm{sec}, 95^{\circ} \mathrm{C} 30 \mathrm{sec}$, $60^{\circ} \mathrm{C} 15 \mathrm{sec}$. Fluorescence from SYBR ${ }^{\circ}$ Green was measured at the end of elongation step. The reaction was carried out in a comparative mode $C_{T}\left(\Delta \Delta C_{T}\right)$. Samples were analyzed in triplicate. Raw data analysis was carried out using the software provided by the Applied Biosystems supplier. Depending on the ultimate objective of the realtime PCR analysis, gene expression analysis or expression cassette copy number estimation, different DNA templates and data processing methods were applied, either cDNA and $\Delta \Delta \mathrm{C}_{\mathrm{T}}$ according to [73], or genomic DNA and modified $\Delta C_{\mathrm{T}}$ according to [46], respectively. For heterologous genes expression analysis, genomic DNA contamination was monitored through setting up reactions with primers specific to XPR2-like terminator. For an expression cassette copy number estimation, the gene encoding actin was used as an endogenous control, present in a single copy per $Y$. lipolytica haploid genome.

\section{Oxidoreductase activity assessment - flow cytometry analysis}

BacLight Redox Sensor ${ }^{\text {Tx }}$ Green Vitality Kit (Thermo Fisher Scientific Inc., Walthman, MA) was used for comparative assessment of oxidoreductase activity in the parental A18 and recombinant NCYC3825 strains. The cells were stained with fluorescent dyes contained in the kit according to the manufacturer's protocol. Appropriately stained cells were analyzed in BD FACS Aria ${ }^{\mathrm{Tx}} \mathrm{III}$ (Becton Dickinson) Cell Sorter. Primary sample line was fitted in the initial $35 \mu \mathrm{m}$ pore-size filter. The instrument setup (optical alignment), stability and performance tests were carried out using CST system (Cytometer Setup and Tracking; Becton Dickinson). FACSFlow solution (Becton Dickinson) was used as sheath fluid. The configuration of the instrument was as follows: $70 \mu \mathrm{m}$ nozzle and $70 \mathrm{psi}$ sheath fluid pressure. The analyzed cells were characterized based on the RedoxSensor ${ }^{\text {Th }}$ Green fluorescence (FL1 detector), excited with $488 \mathrm{~nm}$ blue laser. Threshold line was set on the forward scatter detector (FSC). Data were analyzed with FACS DIVA software (Becton Dickinson). The analysis was preceded by elimination of doublet 
events, in order to eliminate cellular conglomerates from the analysis. Oxidoreductase activity was determined based on the values of median of green fluorescence. Each sample was analyzed in triplicate.

\section{Analytical procedures \\ Optical density, dry cellular weight (DCW), lyophilization, total lipid content and fatty acid profile determination}

Optical density of culture samples was determined by measurement of absorbance at $600 \mathrm{~nm}$ wavelength with Analytik Jena Spectrophotometer and WinASPEKT Software. Dry cellular weight (DCW) was determined through a gravimetric method, after drying the yeast biomass in $105^{\circ} \mathrm{C}$ until constant mass was reached. Lyophilization was carried out in vials in Christ Beta lyophilizator (Christ Germany), applying the following parameters: initial freezing: $-35^{\circ} \mathrm{C}$, drying: condenser $-35^{\circ} \mathrm{C}$, shelf $15^{\circ} \mathrm{C}$, pressure 0.22 mbar, time $40 \mathrm{~h}$. Final drying: shelf $20^{\circ} \mathrm{C}$, pressure 0.18 mbar, time $8 \mathrm{~h}$. Lyophilized cells were revived by rehydrating the lyophilizate in YPD medium.

Dried biomass was further used for intracellular lipid accumulation determination, which was carried out according to standard gravimetric procedure [74]. Known amount of lyophilized sample was placed in a porous cellulose thimble which was put into extraction chamber (TECATOR). Samples were then repeatedly treated with heated petroleum ether for extraction of peroxide-free lipids from dry yeast biomass, then, the remaining solvent was evaporated and the lipid fraction was determined gravimetrically after drying to the constant weight. The results were expressed as a percentage of total lipid fraction per $\mathrm{g}$ of DCW.

For fatty acid profiles determination lyophilized samples were handled according to the procedure described in [75].

\section{HPLC analysis}

Determination of carbon source utilization and metabolites production Determination of carbon source utilization and metabolites production was carried out through HPLC analysis. $0.45 \mu \mathrm{m}$-filtered culture supernatants were analyzed with an Elite LaChrom (VWRHitachi) liquid chromatograph equipped with RI L-2490 detector and a Rezex ROA $300 \times 7.80 \mathrm{~mm}$ column (Phenomenex). 0,005 $\mathrm{N} \mathrm{H}_{2} \mathrm{SO}_{4}$ constituted a mobile phase at a flow rate of $0.6 \mathrm{ml} \mathrm{min}{ }^{-1}$, isocratic. The column temperature was $40^{\circ} \mathrm{C}$. Quantitative and qualitative identification of compounds was carried out with an external standard method, using peak surface for calculations (EzChrom Elite software).

Determination of 2-PE and L-Phe concentration Determination of 2-PE and L-Phe concentration in culture supernatants was carried out through HPLC analysis. $0.45 \mu \mathrm{m}$-filtered culture supernatants were analyzed with an Agilent 1200 liquid chromatograph equipped with a DAD detector (254 $\mathrm{nm})$ and a LiChroCART 125-4 Superspher 100 RP-18e (4 $\mu$ m; MerckMillipore) column. Gradient elution at a flow rate of $1 \mathrm{~mL} \mathrm{~min}{ }^{-1}$ was performed as follows: $0 \mathrm{~min}-5 \%$ of component $\mathrm{B}, 10 \mathrm{~min}$ 65\% B, 11 min - 100\% B, 15 min - 100\% B, 18 min - 5\% B, 23 min - 0\% B. Mobile phase components: A - $0.01 \mathrm{M}$ $\mathrm{HCl}, \mathrm{B}-80: 20$ (acetonitrile: $0.025 \mathrm{M} \mathrm{HCl}$ ). The column temperature was $40^{\circ} \mathrm{C}$. Quantitative and qualitative identification of 2-PE and L-Phe was carried out with an external standard method, using peak surface for calculations.

\section{GC/MS analysis}

Identification of 2-PE in the culture supernatants was carried out through GC/MS analysis. Sample preparation: $0.45 \mu \mathrm{m}$-filtered culture supernatants were transferred onto activated SPE-C18 cartridge (500 mg per $3 \mathrm{~mL}$, TermoScientific). Extraction was carried out with a vacuum SPE station, at a flow rate of $2 \mathrm{~mL} \mathrm{~min}^{-1}$. Following extraction, the column was washed with $20 \mathrm{~mL}$ of deionized water. The non-polar fraction was eluted with $5 \mathrm{~mL}$ of pentane: dichloromethane mix at a ratio of 2:1 (v/v), and dried with $\mathrm{Na}_{2} \mathrm{SO}_{4}$. The extract was concentrated to $500 \mu \mathrm{L}$ and analyzed using GC/MS. GC/MS analysis was carried out with an Agilent 7890A gas chromatograph coupled to a single quadrupole 5975C VL MSD, and equipped with a Supelcowax capillary GC column $(60 \mathrm{~m} \times 0.2 \mathrm{~mm} \times 0.2 \mu \mathrm{m}$; Sigma Aldrich). Mobile phase: helium at a flow rate of $0.8 \mathrm{~mL} \mathrm{~min}^{-1}$. Inlet port temperature $290^{\circ} \mathrm{C}$. Oven program: $1 \mathrm{~min}: 40^{\circ} \mathrm{C}$ followed by $8^{\circ} \mathrm{C}$ per min to $180^{\circ} \mathrm{C}$ for $1 \mathrm{~min}, 1 \mathrm{~min}: 200^{\circ} \mathrm{C}, 20 \mathrm{~min}$ : $240^{\circ} \mathrm{C}$. Mass detector parameters: transfer line $230^{\circ} \mathrm{C}$, scan mode in a range of $33-488 \mathrm{~m} / \mathrm{z}$, electron impact ionization at $70 \mathrm{eV}$.

\section{Additional file}

Additional file 1: Table S1. PCR primers, real-time PCR primers and linkers used in this study.

\section{Competing interests}

The authors declare that they have no competing interests.

\section{Author's contributions}

EC participated in creating the concept of the study, carried out laboratory work and drafted the manuscript. WG participated in creating the concept of the study, coordinated undertakings and approved the manuscript. Both authors read and approved the final manuscript.

\section{Acknowledgments}

This research was funded by the project No 01.01.02-00-074/09 co-funded by The European Union from The European Regional Development Fund within the framework of the Innovative Economy Operational Programme 2007-2013. 
Prof. M. Robak (Dept. of Biotechnology and Food Microbiology, Wroclaw University of Environmental and Life Sciences, Poland) is greatly acknowledged for donating Y. lipolytica strains A18 and A10 and supporting this research with scientific consultations.

The following persons are greatly appreciated, as they contributed to the presented study: P. Kubiak, A. Czerniak, M. Dziadas, W. Juzwa, W. Białas, A. Drożdżyńska, J. Pawlicka, M. Laskowska, B. Kobierna.

Received: 18 August 2013 Accepted: 29 October 2013

Published: 4 November 2013

\section{References}

1. Yang F, Milford HA, Runcang S: Value-added uses for crude glycerol - a byproduct of biodiesel production. Biotechnol Biofuels 2012, 5:13.

2. Petrov K, Petrova P: Enhanced production of 2,3-butanediol from glycerol by forced pH fluctuations. Appl Microbiol Biotechnol 2010, 87:943-949.

3. Zeng AP, Biebl H: Bulk Chemicals from Biotechnology: The Case of 1,3-Propanediol Production and the New Trends. In Tools and Applications of Biochemical Engineering Science, Springer Berlin Heidelberg, Volume 74. Edited by Schügerl K, Zeng A-P. 2002:239-259.

4. Kośmider A, Białas W, Kubiak P, Drożdżyńska A, Czaczyk K: Vitamin B12 production from crude glycerol by Propionibacterium freudenreichii ssp. shermanii: optimization of medium composition through statistical experimental designs. Bioresour Technol 2012, 105:128-133.

5. Liu Y, Zhang YG, Zhang RB, Zhang F, Zhu J: Glycerol/glucose co-fermentation: one more proficient process to produce propionic acid by Propionibacterium acidipropionici. Curr Microbiol 2011, 62:152-158.

6. Choi WJ, Hartono MR, Chan WH, Yeo SS: Ethanol production from biodiesel-derived crude glycerol by newly isolated Kluyvera cryocrescens. Appl Microbiol Biotechnol 2011, 89:1255-1264.

7. Scholten E, Renz T, Thomas J: Continuous cultivation approach for fermentative succinic acid production from crude glycerol by Basfia succiniciproducens DD1. Biotechnol Lett 2009, 31:1947-1951.

8. Papanikolaou S, Aggelis G: Lipid production by Yarrowia lipolytica growing on industrial glycerol in a single-stage continuous culture. Bioresour Technol 2002, 82:43-49.

9. Rymowicz W, Fatykhova AR, Kamzolova SV, Rywińska A, Morgunov IG: Citric acid production from glycerol-containing waste of biodiesel industry by Yarrowia lipolytica in batch, repeated batch, and cell recycle regimes. Appl Microbiol Biotechnol 2010, 87:971-979.

10. Kamzolova SV, Fatykhova AR, Dedyukhina EG, Anastassiadis SG, Golovchenko NP, Morgunov IG: Citric acid production by yeast grown on glycerol-containing waste from biodiesel industry. Food Technol Biotechnol 2011, 49:65-74.

11. Papanikolaou S, Fakas S, Fick M, Chevalot I, Galiotou-Panayotou M, Komaitis M, Marc I, Aggelis G: Biotechnological valorisation of raw glycerol discharged after bio-diesel (fatty acid methyl esters) manufacturing process: Production of 1,3-propanediol, citric acid and single cell oil. Biomass Bioenergy 2008, 32:60-71.

12. Beopoulos A, Cescut J, Haddouche R, Uribelarrea JL, Molina-Jouve C, Nicaud JM: Yarrowia lipolytica as a model for bio-oil production. Prog Lipid Res 2009, 48:375-387.

13. Beopoulos A, Mrozova Z, Thevenieau F, Le Dall MT, Hapala I, Papanikolaou S, Chardot T, Nicaud JM: Control of lipid accumulation in the yeast Yarrowia lipolytica. Appl Environ Microbio/ 2008, 74:7779-7789.

14. Zinjarde SS, Pant AA: Hydrocarbon degraders from tropical marine environments. Mar Pollut Bull 2002, 44:118-121.

15. Finogenova TV, Morgunov IG, Kamzolova SV, Chernyavskaya OG: Organic Acid Production by the Yeast Yarrowia lipolytica: A Review of Prospects. Appl Biochem Microbiol 2005, 41:418-425.

16. Papanikolaou S, Galiotou-Panayotou M, Fakas S, Komaitis M, Aggelis G: Citric acid production by Yarrowia lipolytica cultivated on olive-mill wastewater-based media. Bioresour Technol 2008, 99:2419-2428.

17. Kamzolova SV, Yusupova Al, Vinokurova NG, Fedotcheva NI, Kondrashova MN, Finogenova TV, Morgunov IG: Chemically assisted microbial production of succinic acid by the yeast Yarrowia lipolytica grown on ethanol. Appl Microbiol Biotechnol 2009, 83:1027-1034.

18. Rymowicz W, Rywińska A, Marcinkiewicz M: High-yield production of erythritol from raw glycerol in fed-batch cultures of Yarrowia lipolytica. Biotechnol Lett 2009, 31:377-380.

19. Rabenhorst J, Gatfield I: Method of producing gamma-decalactone using Yarrowia lipolytica strain HR 145 (DSM 12397). 2002. Patent Nr 6451565.
20. Rufino RD, Sarubbo LA, Neto BB, Campos-Takaki GM: Experimental design for the production of tensio-active agent by Candida lipolytica. J Ind Microbiol Biotechnol 2008, 35:907-914

21. Domínguez A, Deive FJ, Sanromàn MA, Longo MA: Biodegradation and utilization of waste cooking oil by Yarrowia lipolytica CECT 1240. Eur J Lipid Sci Technol 2010, 112:1200-1208.

22. Papanikolaou S, Muniglia L, Chevalot I, Aggelis G, Marc I: Accumulation of a cocoa-butter-like lipid by Yarrowia lipolytica cultivated on agro-industrial residues. Curr Microbiol 2003, 46:124-130.

23. Papanikolaou S, Chevalot I, Galiotou-Panayotou M, Komaitis M, Marc I, Aggelis G: Industrial derivative of tallow: a promising renewable substrate for microbial lipid, single-cell protein and lipase production by Yarrowia lipolytica. Electron J Biotechnol 2007, 10:8.

24. Oswal N, Sarma PM, Zinjarde SS, Pant A: Palm oil mill effluent treatment by a tropical marine yeast. Bioresour Technol 2002, 85:35-37.

25. Gonçalves C, Lopes M, Ferreira JP, Belo I: Biological treatment of olive mill wastewater by non-conventional yeasts. Bioresour Technol 2009, 100:3759-3763.

26. Groenewald M, Boekhout T, Neuvéglise C, Gaillardin C, van Dijck PW, Wyss M: Yarrowia lipolytica: Safety assessment of an oleaginous yeast with a great industrial potential. Crit Rev Microbiol 2013, 14. Epub ahead of print.

27. Bankar AV, Kumar AR, Zinjarde SS: Environmental and industrial applications of Yarrowia lipolytica. Appl Microbiol Biotechnol 2009, 84:847-865.

28. Barth G, Gaillardin C: Yarrowia lipolytica. In Nonconventional Yeasts in Biotechnology. Edited by Wolf K. Berlin Heidelberg New York: A Handbook. Springer; 1996:313-388

29. Gellissen G, Kunze G, Gaillardin C, Cregg JM, Berardi E, Veenhuis M, van der Klei I: New yeast expression platforms based on methylotrophic Hansenula polymorpha and Pichia pastoris and on dimorphic Arxula adeninivorans and Yarrowia lipolytica - a comparison. FEMS Yeast Res 2005, 5:1079-1096.

30. Müller S, Sandal T, Kamp-Hansen P, Dalbøge H: Comparison of expression systems in the yeasts Saccharomyces cerevisiae, Hansenula polymorpha, Kluyveromyces lactis, Schizosaccharomyces pombe and Yarrowia lipolytica. Cloning of two novel promoters from Yarrowia lipolytica. Yeast 1998, 14:1267-1283.

31. Madzak C, Gaillardin C, Beckerich JM: Heterologous protein expression and secretion in the non-conventional yeast Yarrowia lipolytica: a review. J Biotechnol 2004, 109:63-81.

32. Madzak C, Nicaud J-M, Gaillardin C: Yarrowia lipolytica. In Production of Recombinant Proteins: Novel Microbial and Eukaryotic Expression Systems. Edited by Gellissen G. Weinheim, FRG: Wiley-VCH Verlag GmbH \& Co. KGaA; 2005. 10.1002/3527603670.ch8

33. Tai M, Stephanopoulos G: Engineering the push and pull of lipid biosynthesis in oleaginous yeast Yarrowia lipolytica for biofuel production. Metab Eng 2013, 15:1-9.

34. Dulermo T, Nicaud JM: Involvement of the G3P shuttle and $\beta$-oxidation pathway in the control of TAG synthesis and lipid accumulation in Yarrowia lipolytica. Metab Eng 2011, 13:482-491.

35. Sharpe PL, Ye RW, Zhu QQ: Carotenoid production in a recombinant oleaginous yeast; 2012. Patent No US2012/0142082 A1.

36. Ye RW, Sharpe PL, Zhu Q: Bioengineering of oleaginous yeast Yarrowia lipolytica for lycopene production. Meth Mol Biol 2012, 898:153-159.

37. Matthäus F, Ketelhot M, Gatter M, Fürst K, Barth G: New Integration Platforms for Gene Expression in Yarrowia lipolytica [abstract]. Yeast 2013, 30(Suppl 1):S132. PS7-17.

38. Juretzek J, Wang HJ, Nicaud JM, Mauersberger S: Comparison of promoters suitable for regulated overexpression of $\beta$-galactosidase in the alkane-utilizing yeast Yarrowia lipolytica. Biotechnol Bioproc Eng 2000, 5:320-326.

39. Raynaud C, Sarçabal P, Meynial-Salles I, Croux C, Soucaille P: Molecular characterization of the 1,3-propanediol (1,3-PD) operon of Clostridium butyricum. Proc Natl Acad Sci USA 2003, 100:5010-5015.

40. Andres S, Wiezer A, Bendfeldt H, Waschkowitz T, Toeche-Mittler C, Daniel R: Insights into the genome of the enteric bacterium Escherichia blattae: cobalamin (B12) biosynthesis, B12-dependent reactions, and inactivation of the gene region encoding B12-dependent glycerol dehydratase by a new mu-like prophage. J Mol Microbiol Biotechnol 2004, 8:150-168.

41. Walczak E: Genetic transformation of selected strains of Yarrowia lipolytica yeast. Ph.D, Thesis, Wroclaw University of Environmental and Life Sciences, Department of Food Science and Nutrition; 2009. 
42. Marx H, Mecklenbräuker A, Gasser B, Sauer M, Mattanovich D: Directed gene copy number amplification in Pichia pastoris by vector integration into the ribosomal DNA locus. FEMS Yeast Res 2009, 9:1260-1270.

43. Le Dall MT, Nicaud JM, Gaillardin C: Multiple-copy integration in the yeast Yarrowia lipolytica. Curr Genet 1994, 26:38-44.

44. Steinborn G, Gellissen G, Kunze G: Assessment of Hansenula polymorpha and Arxula adeninivorans-derived rDNA-targeting elements for the design of Arxula adeninivorans expression vectors. FEMS Yeast Res 2005, 5:1047-1054.

45. Casarégola S, Feynerol C, Diez M, Fournier P, Gaillardin C: Genomic organization of the yeast Yarrowia lipolytica. Chromosoma 1997, 106:380-390.

46. Liew SN, Lazaruk K, Wong L, Stevens J, Livak K: Determining the copy number of genes using real-time quantitative PCR. Appl Biosyst Progr 2005. \#1037/W 127PR11-01.

47. Romanos MA, Boyd A: A transcriptional barrier to expression of cloned toxin genes of the linear plasmid k1 of Kluyveromyces lactis: evidence that native k1 has novel promoters. Nucleic Acids Res 1988, 16:7333-7350.

48. Romanos MA, Makoff AJ, Fairweather NF, Beesley KM, Slater DE, Rayment FB, Payne MM, Clare JJ: Expression of tetanus toxin fragment $C$ in yeast: gene synthesis is required to eliminate fortuitous polyadenylation sites in AT-rich DNA. Nucleic Acids Res 1991, 19:1461-1467.

49. Romanos MA, Scorer CA, Clare JJ: Foreign gene expression in yeast: a review. Yeast 1992, 8:423-488

50. Mellitzer A, Weis R, Glieder A, Flicker K: Expression of lignocellulolytic enzymes in Pichia pastoris. Microb Cell Fact 2012, 11:61.

51. Zhang B, Rong C, Chen H, Song $Y$, Zhang H, Chen W: De novo synthesis of trans-10, cis-12 conjugated linoleic acid in oleaginous yeast Yarrowia lipolytica. Microb Cell Fact 2012, 11:51

52. Tanaka M, Tokuoka M, Shintani T, Gomi K: Transcripts of a heterologous gene encoding mite allergen Der $\mathrm{f} 7$ are stabilized by codon optimization in Aspergillus oryzae. Appl Microbiol Biotechnol 2012, 96:1275-1282.

53. Bhave SL, Chattoo BB: Expression of Vitreoscilla hemoglobin improves growth and levels of extracellular enzyme in Yarrowia lipolytica. Biotechnol Bioeng 2003, 84:658-666.

54. Luo Y, Kou X, Ding X, Hu S, Tang Y, Li W, Huang F, Yang Q, Chen H, Xia L: Promotion of spinosad biosynthesis by chromosomal integration of the Vitreoscilla hemoglobin gene in Saccharopolyspora spinosa. Sci China Life Sci 2012, 55:172-180.

55. Wang T, Bai L, Zhu D, Lei X, Liu G, Deng Z, You D: Enhancing macrolide production in Streptomyces by coexpressing three heterologous genes. Enzyme Microb Technol 2012, 50:5-9.

56. Wang $X$, Sun Y, Shen X, Ke F, Zhao H, Liu Y, Xu L, Yan Y: Intracellular expression of Vitreoscilla hemoglobin improves production of Yarrowia lipolytica lipase LIP2 in a recombinant Pichia pastoris. Enzyme Microb Technol 2012, 50:22-28.

57. Wu JM, Fu WC: Intracellular co-expression of Vitreoscilla hemoglobin enhances cell performance and $\beta$-galactosidase production in Pichia pastoris. J Biosci Bioeng 2012, 113:332-337.

58. Chen W, Hughes DE, Bailey JE: Intracellular expression of Vitreoscilla hemoglobin alters the aerobic metabolism of Saccharomyces cerevisiae. Biotechnol Prog 1994, 10:308-313.

59. Chien LJ, Lee CK: Expression of bacterial hemoglobin in the yeast, Pichia pastoris, with a low O2-induced promoter. Biotechnol Lett 2005, 27:1491-1497.

60. Suthar DH, Chattoo BB: Expression of Vitreoscilla hemoglobin enhances growth and levels of alpha-amylase in Schwanniomyces occidentalis. Appl Microbiol Biotechnol 2006, 72:94-102.

61. Papanikolaou S, Muniglia L, Chevalot I, Aggelis G, Marc I: Yarrowia lipolytica as a potential producer of citric acid from raw glycerol. J Appl Microbiol 2002, 92:737-744.

62. Rywińska A, Rymowicz W, Marcinkiewicz M: Valorization of raw glycerol for citric acid production by Yarrowia lipolytica yeast. Electron J Biotechnol 2010, 13:1.

63. Makri A, Fakas S, Aggelis G: Metabolic activities of biotechnological interest in Yarrowia lipolytica grown on glycerol in repeated batch cultures. Bioresour Technol 2010, 101:2351-2358.

64. André A, Chatzifragkou A, Diamantopoulou P, Sarris D, Philippoussis A Galiotou-Panayotou M, Komaitis M, Papanikolaou S: Biotechnological conversions of bio-diesel-derived crude glycerol by Yarrowia lipolytica strains. Eng Life Sci 2009, 9:468-478.
65. Fontanille P, Kumar V, Christophe G, Nouaille R, Larroche C: Bioconversion of volatile fatty acids into lipids by the oleaginous yeast Yarrowia lipolytica. Bioresour Technol 2012, 114:443-449.

66. Papanikolaou S, Chevalot I, Komaitis M, Marc I, Aggelis G: Single cell oil production by Yarrowia lipolytica growing on an industrial derivative of animal fat in batch cultures. Appl Microbiol Biotechnol 2002, 58:308-312.

67. Xue Z, Sharpe PL, Hong SP, Yadav NS, Xie D, Short DR, Damude HG, Rupert RA, Seip JE, Wang J, Pollak DW, Bostick MW, Bosak MD, Macool DJ, Hollerbach DH, Zhang H, Arcilla DM, Bledsoe SA, Croker K, McCord EF, Tyreus BD, Jackson EN, Zhu Q: Production of omega-3 eicosapentaenoic acid by metabolic engineering of Yarrowia lipolytica. Nat Biotechnol 2013, 31:734-740.

68. Zhang B, Chen H, Li M, Gu Z, Song Y, Ratledge C, Chen YQ, Zhang H, Chen W: Genetic engineering of Yarrowia lipolytica for enhanced production of trans-10, cis-12 conjugated linoleic acid. Microb Cell Fact 2013, 12:70.

69. Bellou S, Moustogianni A, Makri A, Aggelis G: Lipids containing polyunsaturated fatty acids synthesized by Zygomycetes grown on glycerol. Appl Biochem Biotechnol 2012, 166:146-158.

70. Celińska E, Kubiak P, Białas W, Dziadas M, Grajek W: Yarrowia lipolytica: the novel and promising 2-phenylethanol producer. J Ind Microbiol Biotechnol 2013, 40:389-392.

71. Etschmann MM, Bluemke W, Sell D, Schrader J: Biotechnological production of 2-phenylethanol. Appl Microbiol Biotechnol 2002, 59:1-8.

72. Sambrook J, Russell D: Molecular Cloning: A Laboratory Manual. 3rd edition. Cold Spring Harbor Laboratory Press; 2001. ISBN 978-0-87969-577-4.

73. Livak KJ, Schmittgen TD: Analysis of relative gene expression data using real-time quantitative PCR and the 2(-Delta Delta C(T)) Method. Methods 2001, 25:402-408.

74. Soxhlet F: Die gewichtsanalytische Bestimmung des Milchfettes. Polytechnisches J (Dingler's) 1879, 232:461.

75. Cieślak A, Machmüller A, Szumacher-Strabel M, Scheeder MRL: A comparison of two extraction methods used to quantify the C18 fatty acids in feed and digesta of ruminants. J Anim Feed Sci 2009, 18:362-367.

doi:10.1186/1475-2859-12-102

Cite this article as: Celińska and Grajek: A novel multigene expression construct for modification of glycerol metabolism in Yarrowia lipolytica. Microbial Cell Factories 2013 12:102.

\section{Submit your next manuscript to BioMed Central and take full advantage of:}

- Convenient online submission

- Thorough peer review

- No space constraints or color figure charges

- Immediate publication on acceptance

- Inclusion in PubMed, CAS, Scopus and Google Scholar

- Research which is freely available for redistribution
C Biomed Central 